\title{
Localized expression of sloppy paired protein maintains the polarity of Drosophila parasegments
}

\author{
Kenneth M. Cadigan, ${ }^{1}$ Ueli Grossniklaus, ${ }^{2}$ and Walter J. Gehring \\ Biozentrum, University of Basel, CH-4056 Basel, Switzerland
}

\begin{abstract}
During germ-band extension in the Drosophila embryo, intercellular communication is required to maintain gene expression patterns initiated at cellular blastoderm. For example, the wingless (wg) single-cell-wide stripe in each parasegment (PS) is dependent on a signal from the adjacent, posterior cells, which express engrailed (en). This signal is thought to be the hedgehog $(h h)$ gene product, which antagonizes the activity of patched (ptc), a repressor of $w g$ expression. Genetic evidence indicates that the $h h$ signal is bidirectional, but $w g$ transcription is only derepressed on the anterior side of the en/hh stripes. To explain the asymmetric response of the $\mathrm{wg}$ promoter to the hh signal, current models predict that each PS is divided into cells that are competent to express either wg or en, but not both. The sloppy paired (slp) locus contains two transcription units, both encoding proteins containing a forkhead domain, a DNA-binding motif. Removal of slp gene function causes embryos to exhibit a severe pair-rule/segment polarity phenotype. We show that the en stripes expand anteriorly in slp mutant embryos and that slp activity is an absolute requirement for maintenance of $w g$ expression at the same time that $w g$ transcription is dependent on $h h$. The slp proteins are expressed in broad stripes just anterior of the en-positive cells, overlapping the narrow wg stripes. We propose that by virtue of their ability to activate $w g$ and repress en expression, the distribution of the slp proteins define the wg-competent and en-competent groups. Consistent with this hypothesis, ubiquitous expression of slp protein throughout the PS abolishes en expression and, in ptc mutant embryos, results in a near ubiquitous distribution of $\mathrm{wg}$ transcripts. In addition to demonstrating the role of $s l p$ in maintaining segment polarity, our results suggest that $s l p$ works in, or parallel with, the ptc/hh signal transduction pathway to regulate $w g$ transcription.
\end{abstract}

[Key Words: sloppy paired; forkhead domain; segment polarity; wingless; engrailed]

Received January 20, 1994; revised version accepted March 2, 1994.

The establishment of segmentation in the Drosophila melanogaster embryo has become a paradigm for the study of pattern formation. Mutant screens have found several classes of zygotic genes specifically affecting this process, which serve to subdivide the embryo into increasingly smaller units. Gap gene mutations result in deletions of several adjacent segments; pair-rule mutants lack alternate segments; and segment polarity mutants lack portions of each segment (Nüsslein-Volhard and Wieschaus 1980). These genes act in a hierarchial manner, with information flowing from the gap genes to the pair-rule, and these in turn regulate the segment polarity genes (Akam 1987; Scott and Carroll 1987; Ingham 1988).

Two important targets of this regulation are the seg-

Present addresses: ${ }^{1}$ Howard Hughes Medical Institute and Department of Developmental Biology, Beckman Center, Stanford University School of Medicine, Stanford California 94305-5428 USA; ${ }^{2}$ Cold Spring Harbor Laboratory, Cold Spring Harbor, New York 11724 USA. ment polarity genes wingless ( $\mathrm{wg}$ ) and engrailed (en). wg is required for the formation of naked cuticle in the posterior portion of each segment (Nüsslein-Volhard and Wieschaus 1980; Baker 1988; Bejsovec and Martinez Arias 1991; Noordermeer et al. 1992) and en for the generation of segmental borders (Kornberg 1981; DiNardo and O'Farrell 1987; Martinez-Arias and White 1988). The two genes are expressed during embryogenesis in adjacent but nonoverlapping stripes of a single-segment periodicity, with the $w g$ stripes located anterior to those of $e n$. At full germ-band extension, the parasegmental grooves, the first overt sign of segmentation in Drosophila embryos (Martinez-Arias and Lawrence 1985), form where the $w g$ and en stripes abut (Ingham et al. 1985a; Baker 1987; van den Heuvel et al. 1989).

After establishment as single-cell-wide stripes at cellular blastoderm, wg and en are required to maintain each other's expression during germ-band elongation (DiNardo et al. 1988; Martinez Arias et al. 1988). Because they are not expressed in the same cells, this regulation 
must involve cell-cell communication. The wg gene encodes a cysteine-rich protein (Rijsewijk et al. 1987) that is secreted (van den Heuvel et al. 1989, 1993; Gonzalez et al. 1991) and is thought to be the signal to the en cells. The en gene contains a homeo box (Fiose et al. 1985; Poole et al. 1985) and encodes a nuclear protein (DiNardo et al.1985), so it is unlikely to be the signal to the $w g$ cells. The signal is thought to be the product of the hedgehog $(h h)$ gene, which is expressed in stripes coincident with those of $e n$. $h$ h is predicted to encode a cellsurface protein (Lee et al. 1992; Mohler and Vani 1992; Tabata et al. 1992) and appears to be processed to form a secreted protein (Lee et al. 1992; Taylor et al. 1993). The $h h$ gene product interferes with the activity of patched $(p t c)$, a protein with several predicted membrane-spanning domains (Hooper and Scott 1989; Nakano et al. 1989) found at the cell surface (Ingham et al. 1991; Taylor et al. 1993), which functions as a repressor of $w g$ expression (Ingham et al. 1991; Bejsovec and Wieschaus 1993). Thus, a model has emerged where en protein activates $h h$ transcription, and the secreted $h h$ protein somehow interferes with the inhibitory signal that the $p t c$ protein sends to the nucleus of the wg-expressing cells.

During germ-band extension, the regulation of ptc expression is in many ways similar to that of $w g$. ptc represses its own transcription and hh somehow antagonizes this activity (Hildalgo and Ingham 1990; Forbes et al. 1993). This leads to a ptc expression pattern of singlecell-wide stripes on either side of the $e n / h h$ stripes (Hooper and Scott 1989; Nakano et al. 1989), presumably because these are the only cells that receive enough $h h$ protein to inactivate ptc (Ingham 1993). In constrast, wg transcription is only derepressed by $h h$ in cells on the anterior side of the $e n / h h$ expression domain. This raises the question of how bidirectionally secreted signals, for example, the $h h$ protein, can act to generate the polarized responses that are observed in the embryonic segments, for example, expression of $w g$ on only one side of the en stripes (Hooper and Scott 1992). One possibility is that in addition to $h h, w g$ transcription at this time depends on preexisting $w g$ protein. Thus, $w g$ autoactivation would maintain the asymmetric distribution of $w g$ transcripts that was originally set up by the pair-rule genes. However, analysis of wg expression in pair-rule, $p t c$ double mutants indicates that regulation of $w g$ expression by $h h$ and $p t c$ is not coupled to the earlier acting pair-rule genes (Ingham and Hidalgo 1993). Therefore, to explain the polarized response of the wg promoter to the $h h$ protein, Ingham and co-workers (1991) proposed that each parasegment (PS) is divided into two groups; the cells in the posterior half of the PS are wg-competent, and the anterior half are en-competent. They suggested that these competency groups are established at cellular blastoderm by the pair-rule genes and provide the foundation on which asymmetry is later maintained.

This report is concerned with the role of the sloppy paired $|s I p\rangle$ locus in segmentation. The locus contains two transcription units, slp1 and slp2, both encoding proteins containing a forkhead domain /Grossniklaus et al. 1992), a DNA-binding motif (Weigel and Jäckle 1990; Clark et al. 1993). Deletion of both slp genes causes a severe pair-rule/segment polarity defect /Grossniklaus et al. 1992). The results presented here demonstrate that $s l p$ is an activator of $w g$ and a repressor of $e n$ expression, and through these activities, the distribution of slp defines the competency groups described above, that is, cells lacking slp protein are en-competent and cells containing $s l p$ protein are $w g$-competent. This hypothesis was confirmed by ubiquitous expression of $s l p$ /via a heat shock promoter), which abolishes en expression and, in $p t c$ mutant embryos, where $w g$ expression is largely independent of $e n$ and $h h$ (Ingham et al. 1991; Tabata et al. 1992; Bejsovec and Wieschaus 1993), results in a near ubiquitous expression of $w g$. Thus, the localized expression of $s l p$ is required to maintain the proper anterior border of the en stripes and to restrict $\mathrm{wg}$ expression to one side of the en/hh domain.

\section{Results}

slp mutant embryos have characteristics of pair-rule mutants (i.e., fusions of abdominal segments A1-A2, A3-A4, etc.), as well as features of wg-class segment polarity mutants, for example, replacement of naked cuticle by denticles (Fig. 1B). This report is concerned only with the phenotype of embryos lacking both slp gene activities. The respective contributions of $\operatorname{slp} 1$ and $\operatorname{slp} 2$

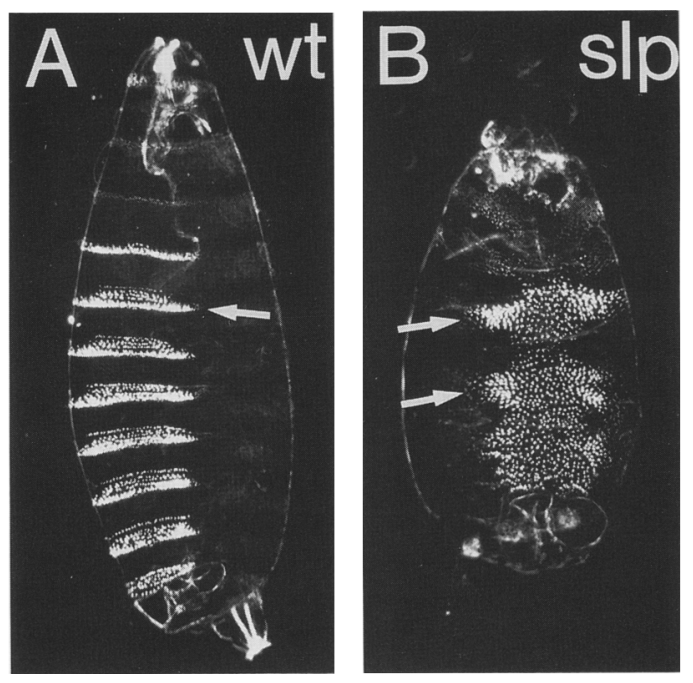

Figure 1. The cuticular phenotype of a slp null mutant. $(A)$ Ventral view of a wild-type (wt) first instar larvae, the trunk of which is divided into three thoracic and eight abdominal segments (A1-A8). The anterior half of each segment contains a trapezoidal array of hooks known as a denticle belt (the arrow indicates the $A 2$ dentricle belt $)$. $(B)$ Terminally differentiated embryo homozygous for $\triangle 34 \mathrm{~B}$, a deficiency removing both $s l p$ transcripts. Notice the pair-rule type fusions of A1-A2 and A3A4 (see arrows). The naked cuticle normally found in the posterior part of each segment is either missing or replaced by denticles. 
to the phenotypes described here are reported elsewhere (Grossniklaus et al. 1992; Cadigan et al. 1994).

\section{Expression of segment polarity and pair-rule genes} in slp mutants

To understand the slp mutant phenotype in more detail, we examined the expression of all pair-rule and zygotic segment polarity genes for which probes were available in $s l p$ mutants. The most instructive probes in regard to explaining the $s l p$ mutant cuticle phenotype were those for $w g$ and en (Fig. 2). en expression is an excellent marker for segmentation, for example, pair-rule mutants lacking alternate segments also lack the corresponding en stripes (DiNardo and O'Farrell 1987; Martinez-Arias and White 1988). wg is believed to specify naked cuticle in each segment and all the zygotic wg-class segment polarity genes are thought to exert their effects through wg (Peifer and Bejsovec 1992).

In slp mutant embryos, en expression is initiated normally, except for a wider stripe in the maxillary $(\mathrm{Mx})$ segment primordia (data not shown; DiNardo and O'Farrell 1987). However, during germ-band elongation (stage 8; stages correspond to those described in Campos-Ortega and Hartenstein 1985), all of the en stripes widen (Fig. 2, cf. A and B). When germ-band elongation is complete (stage 10), the odd-numbered PS en stripes are greatly reduced in intensity, and the even-numbered ones are one to two cells wider than wild type (Fig. 2, cf. $\mathrm{C}$ and $\mathrm{D}$.

$w g$ expression is also initiated normally in $s l p \mathrm{mu}-$ tants, but during early germ-band extension (stage 7), the even-numbered PS stripes begin to fade, so that by stage 9 , they are completely gone (Fig. 2F). Shortly thereafter, the remaining stripes rapidly fade and are completely gone at early stage 10 (Fig. 2H). The misexpression of en and $w g$ in the head and gnathal region (see legend to Fig. 2) will be discussed in more detail elsewhere (U. Grossniklaus, K.M. Cadigan, and W.J. Gehring, in prep.).

Figure 3 shows the expression of some other segment polarity genes in slp mutants. In the trunk, $h h$ is expressed in the same cells as en and is regulated in an identical fashion (Lee et al. 1992; Mohler and Vani 1992; Tabata et al. 1992). Likewise, in slp embryos hh expression parallels that of en (Fig. 3B). The gooseberry (gsb) gene is expressed in two-cell-wide stripes overlapping the wg stripes and the anterior half of the en stripes (Gutjahr et al. 1993). In $s l p$ embryos, gsb mRNA decays in a fashion similar to wg but with a temporal lag. At early stage 10 , the stripes overlapping the even-numbered PS wg stripes are completely gone from the epidermis but, unlike $w g$, the remaining gsb stripes are still largely intact (Fig. 3D), though they too will fade by stage 11. At stage $11, p t c$ is expressed in single-cell stripes on either side of the en domains (Fig. 3E; Hooper and Scott 1989; Nakano et al. 1989). In slp mutants, only half of these doublets are found, presumably the ones flanking
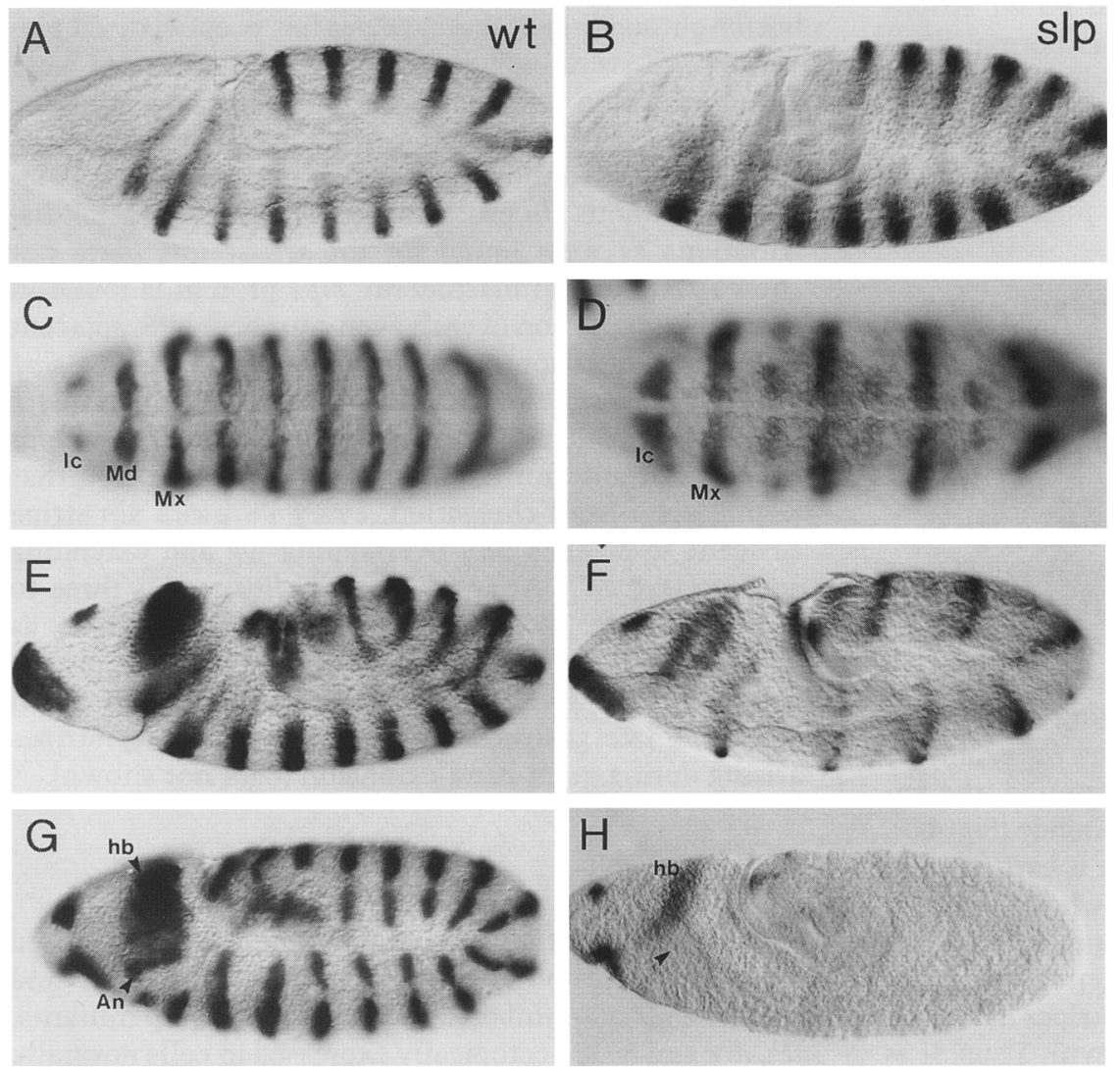

Figure 2. Distribution of en $(A-D)$ and $w g$ transcripts $(E-H)$ in wild type (left) and $\operatorname{slp}(\Delta 34 \mathrm{~B})$ mutants (right). During stage 8, the en stripes widen so that by early stage 9 , they are significantly wider than wild type (cf. $A$ and $B$ ). Subsequently, the en stripes in the odd-numbered PSs begin to fade, as seen in the ventral view in $D$. The mandibular ( $\mathrm{Md}$ ) stripe is completely gone in $s l p$ mutants, and the intercalary (Ic) domain is greatly expanded. At the beginning of germ-band extension, the wg stripes in the even-numbered PSs begin to fade and are completely gone by stage $9(F)$. The head blob (hb) wg domain is greatly reduced and the antennal domain is absent (cf. $G$ and $H$; see arrowheads). The remaining stripes fade rapidly and are completely gone by early stage $10(H)$. (Mx) maxillary segment primodia. 
Figure 3. Distribution of $h h(A, B), g s b \mid C$, $D)$, and ptc transcripts $(E, F)$ in wild-type (top) and $\operatorname{slp}(\Delta 34 \mathrm{~B}$ ) mutants (bottom). The expression of $h h$ in the trunk is identical to that of $e n$, i.e., a widening of the stripes and the odd-numbered PS stripes fading $(B)$. The $g s b$ stripes in the even-numbered PSs fade during germ-band extension so that only neuroblast expression is seen at stage 10 $(D)$. The remaining stripes fade during stage 11. In early stage 12 wild-type embryo $p t c$ is
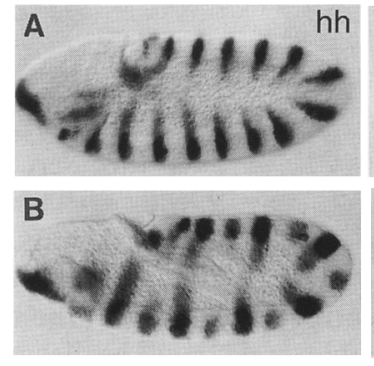
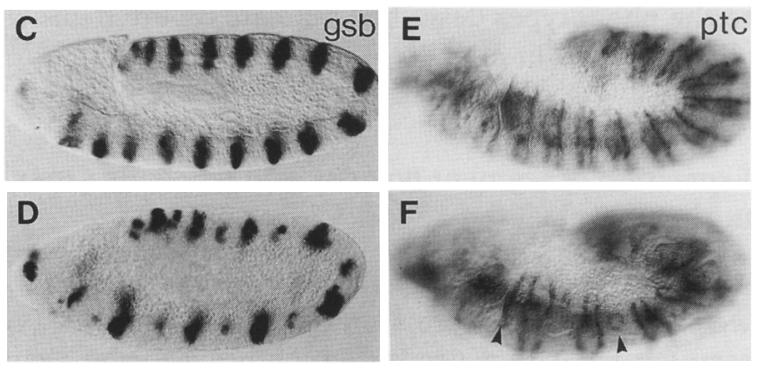

expressed in single-cell stripes on each side of the en stripes (E; see Hooper and Scott 1989; Nakano et al. 1989). In slp mutants at this stage only half of the stripe doublets remain (though some ptc expression remains between the doublets; see arrowheads), and the space between each stripe is greater than in wild type $(F)$.

the even-numbered PS en stripes, although some remnants between them also remain (Fig. 3F).

We have restricted our analysis of pair-rule gene expression in $s l p$ mutants from syncitial blastoderm to mid-germ-band extension (stage 8), the time when these genes are thought to act in the segmentation hierarchy. runt (run), odd-skipped (odd), and hairy $(h)$ show no detectable misexpression in slp embryos (data not shown). paired (prd) has a slight widening of its first and second stripes, but no other difference (data not shown; Baumgartner and Noll 1991). The pattern of fushi tarazu (ftz) also begins normally, but during late gastrulation/early germ-band elongation, seven extra stripes arise (Fig. 4A). Double-staining experiments show that these extra stripes are in the posterior-most cells of each even-numbered PS, adjacent to the odd-numbered PS en stripes (Fig. 4B). even-skipped (eve) expression is normal until stage 8 , when it broadens, coinciding with the en stripe broadening (Fig. 4C, D).

\section{Direction of en expansion and PS groove formation in slp mutants}

To determine the direction of en domain broadening in $s l p$ embryos, two experiments were performed. The first was to examine $g s b$ and en expression in $s l p$ embryos. In wild type, as stated above, gsb is expressed in two-cell wide-stripes, with the posterior-most cells overlapping with the anterior-most en cells (Fig. 4E). In late stage 9 slp mutants, the even-numbered PS en stripes are widened, and there is a two-cell overlap with the $g s b$ stripes (Fig. 4F). The simplest explanation for this is that the en stripes have expanded in an anterior direction. To confirm this, we determined $e n$ and $l a c Z$ distribution in $s l p$ mutants containing a chromosome carrying $\mathrm{P}[\mathrm{ftz}-\mathrm{lacC}]$, which puts lacZ under the control of the $f t z$ promoter (Hiromi et al. 1985). In a wild-type background, the anterior border of $l a c Z$ and en expression coincide (Fig. 4G). In a $s l p$ mutant background, however, $e n$ is expressed in a row of cells anterior of $\operatorname{lac} Z$ (Fig. $4 \mathrm{H}$ ). We have found no evidence for the anterior border of $f t z$ expression changing in slp mutants, for example, the anterior borders of $f t z$ and $e n$ coincide (Fig. 4B) until the $f t z$ stripes fade prior to the en stripes widening (data not shown). Thus, it is extremely unlikely that the $l a c Z$ stripes have shifted posteriorly in the $s l p$ mutants, and we conclude that in slp mutants, the en stripes expand anteriorly.

The first sign of segmentation in Drosophila embryos is the parasegmental grooves, which are first apparent at early stage 10 (Campos-Ortega and Hartenstein 1985; Martinez-Arias and Lawrence 1985). en is found just posterior of the grooves (Ingham et al. 1985a). In slp mutants, the grooves still form to the anterior of en (Fig. 4I); therefore, the formation of the PS grooves in slp mutants is one or two cells anterior that of wild type.

\section{Expression pattern of slp protein}

A detailed description of $\operatorname{slp} 1$ and $\operatorname{slp} 2$ transcript distribution throughout embryogenesis has been reported previously (Grossniklaus et al. 1992). slp transcripts were found in stripes two cells wide, initially with a double and then a single segment periodicity. The transcripts were localized to the posterior half of each PS. Antibodies against both $s l p$ proteins show identical spatial distributions as were found for the transcripts /data not shown). At cellular blastoderm, slp1 protein is found in the posterior portion of each even-numbered PS, adjacent to, but not overlapping, eve protein (Fig. 5A). The slp1 protein is localized to the nucleus as is that of slp2 (data not shown). During gastrulation, the secondary stripes appear, just anterior of the $f t z$ stripes (Fig. 5B), so that during germ-band elongation, every PS has a slp stripe adjacent to en (Fig. 5E), overlapping $w g$ and extending anterior (Fig. 5C). At stage 10, this slp stripe is three to four cells wide. The slp2 protein expression pattern, as was reported previously for that of the transcript, develops later than slp1. Protein is first detected in seven stripes at late gastrulation, with the secondary stripes arising during germ-band extension (data not shown).

\section{Is activation of $\mathrm{wg}$ expression by slp direct?}

Consistent with its expression in $w g$ cells, slp is required for maintenence of $w g$ expression, first in the even- and then in the odd-numbered PSs. However, in slp mutants, $f t z, e v e$ and $e n$ are ectopically expressed in cells normally 

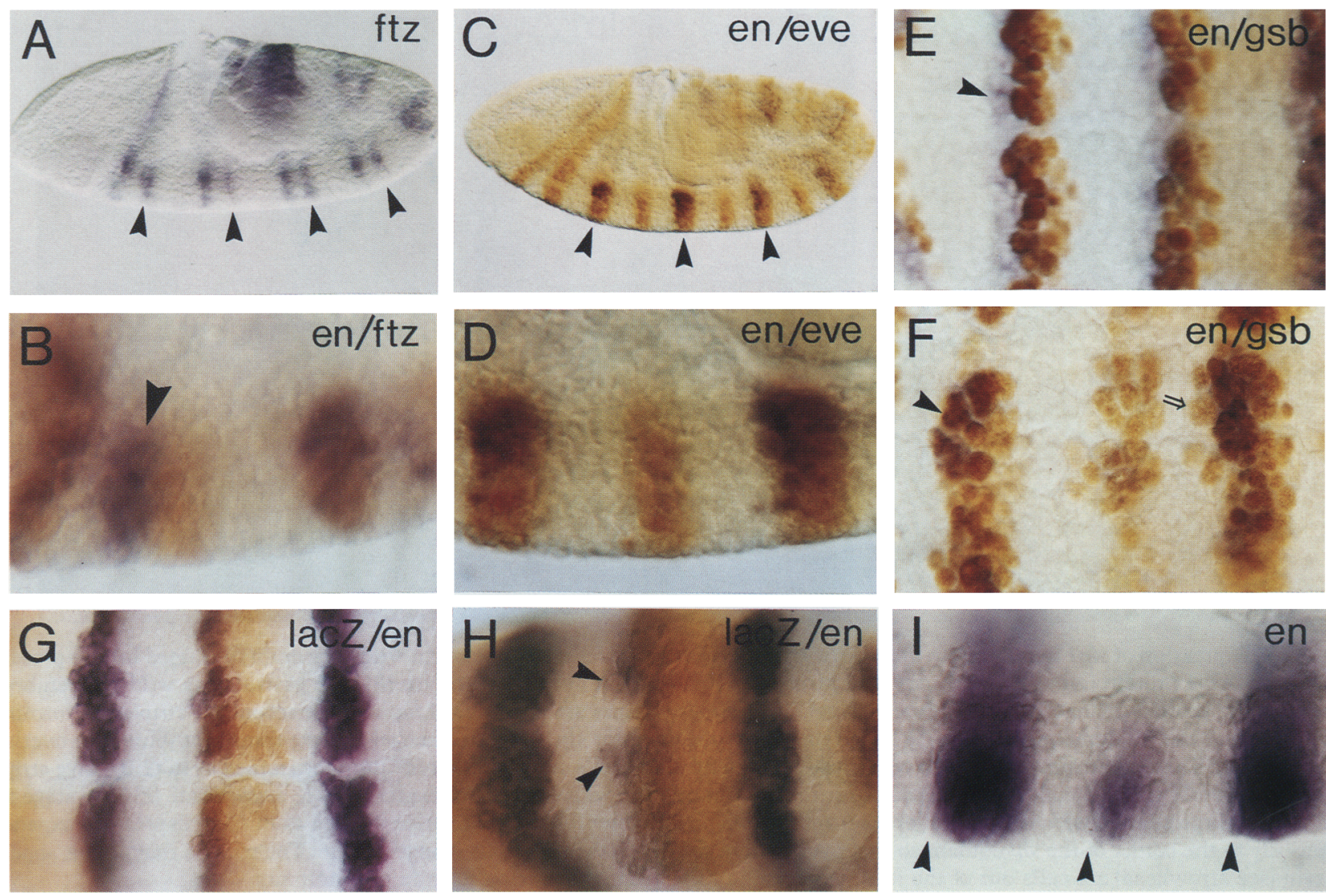

Figure 4. Derepression of $f t z$, eve, and en expression in $\operatorname{slp}(\Delta 34 \mathrm{~B})$ mutants. $(A) f t z$ protein distribution in a slp mutant at stage 8 . During germ-band extension, seven additional stripes arise in the posterior part of the even-numbered PSs (arrows). (B) $s l p$ mutant stained for en (orange) and ftz (blue) proteins. The extra stripe in PS2 (arrow) lies just anterior to the PS3 en stripe. (C) Stage 8 slp mutant stained for en (orange) and eve protein (blue; overlap is black). The en stripes in the odd-numbered PSs (arrows) are wider than the even-numbered ones, which will broaden shortly afterward. $\{D\}$ Higher magnification of $C$. Note that the anterior border of the eve and $e n$ stripes coincide. $(E)$ Late stage 9 wild-type embryo stained for en protein (orange) and gs $b$ transcript (blue). At this time, gsb is expressed in a two-cell stripe that straddles the PS border, so that the posterior-most row of cells overlap with the anterior-most row of en cells (arrow). (F) slp embryo stained as in E. The $e n$ stripes in the odd-numbered PS are wider, and the anterior border of the $e n$ and $g s b$ stripes now coincide (arrow) or occasionally en-staining cells are found anterior of the gsb stripes (open arrow). (G) Stage 8 embryo containing a $f t z-l a c Z$ construct that expresses $l a c Z$ in a $f t z$-like pattern. The embryo is stained for lac $Z$ protein (orange) and en transcript (blue). The anterior border of the en and lacZ stripes are identical. (H) Stage 8 slp mutant containing the $f t z-l a c Z$ transgene stained as in $G$. The anterior-most en cells of the even-numbered PS shown (arrows) does not stain for lac $Z$, indicating the expansion of the $e n$ stripes in $s l p$ mutants is in the anterior direction. (I) en expression in a stage 10 slp embryo. The parasegmental grooves are indicated (arrows).

expressing $w g$. There is strong evidence for $f t z$ and $e v e$ being repressors of $w g$ transcription (Ingham et al. 1988; Ish-Horowicz et al. 1989; Manoukian and Krause 1992), and $e n$ has been suggested to repress wg expression (Heemskerk et al. 1991). It may be that slp is not a direct activator of $w g$ transcription but, rather, activates $w g$ expression by repressing a $w g$ repressor(s). This possibility can be tested by analyzing $w g$ expression in the appropriate double mutants. If $s l p$ is activating $w g$ by repressing a $w g$ repressor, then $w g$ expression in $s l p \mathrm{mu}^{-}$ tants lacking this repressor should persist longer than in slp mutants alone.

A dramatic derepression of $w g$ transcipts is seen in $f t z$ and eve mutant embryos, such that all the cells in the even- or odd-numbered PSs express $w g$, respectively (Ingham et al. 1988). In eve mutants, the PS-wide $w g$ stripes fade during germ-band elongation (Ingham and Hidalgo 19931. wg mRNA in slp, eve double mutants behaves similarly as in eve embryos, except that the disappearance of $w g$ transcripts occurs slightly earlier (data not shown). In the crosses performed to create $s l p ; f t z \mathrm{mu}$ tants, only $1 / 16$ of the progeny are double mutants. We were not able to unambiguously identify double mutants after staining for $w g$ transcripts (data not shown). We reasoned that we could assay the presence of $w g$ in the even-numbered PSs by monitoring the adjacent en stripes, which require $w g$ expression for proper maintanence (Bejsovec and Martinez Arias 1991; Heemskerk et 

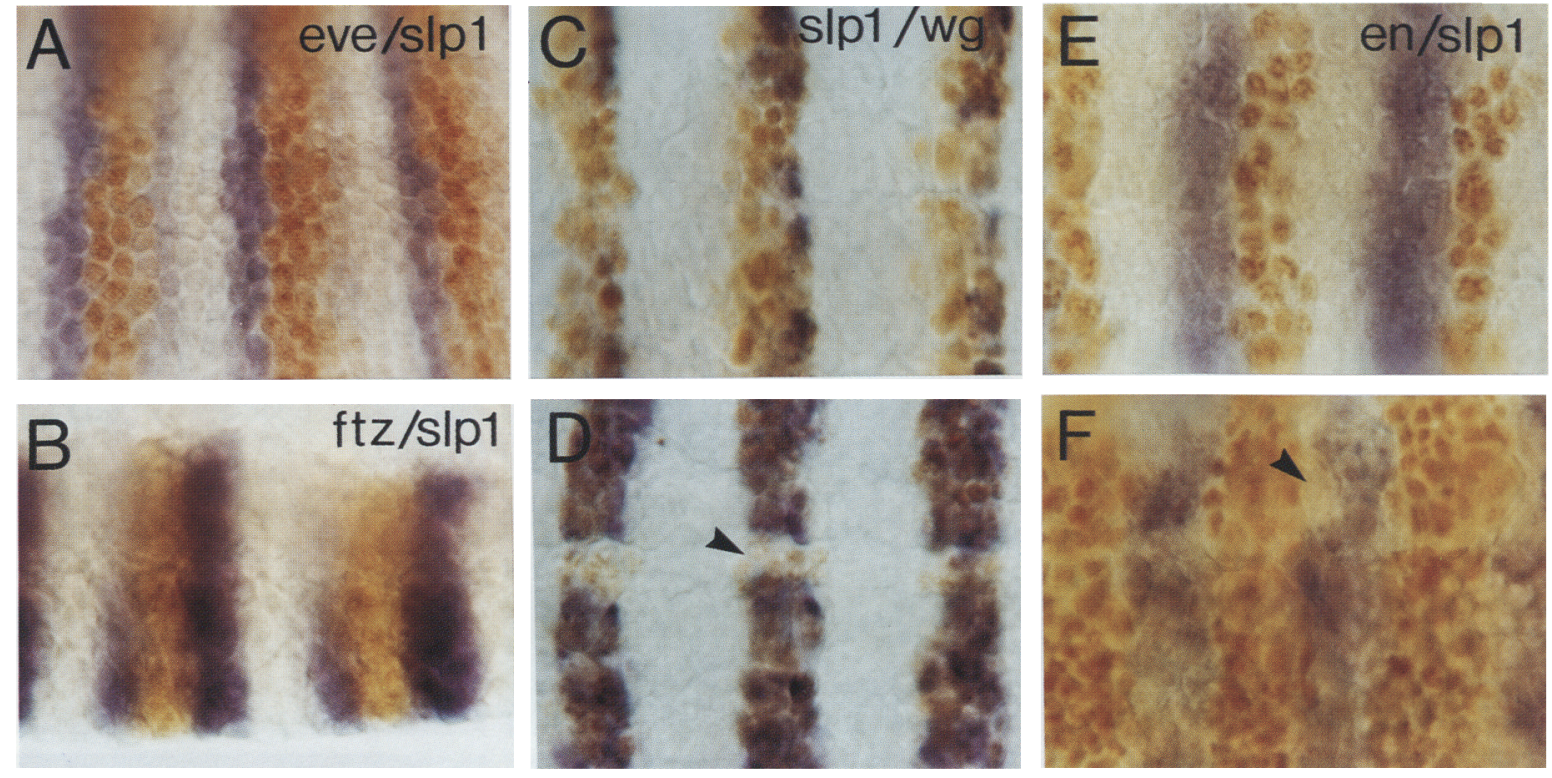

Figure 5. Expression of $\operatorname{slp} 1$ in relation to other segmentation genes. $(A)$ Cellular blastoderm wild-type embryo stained for eve protein (orange) and $\operatorname{slp} 1$ protein (blue). The primary $\operatorname{slp} 1$ stripes are just anterior of the eve stripes. $(B)$ Late gastrulating wild-type embryo stained for $f t z$ protein (orange) and $s l p 1$ protein (blue). The primary stripes are posterior of $f t z$, and the secondary stripes are forming just anterior of the $\mathrm{ftz}$ domain. $|C|$ Stage 10 wild-type embryo stained for slp1 protein (orange) and wg transcript (blue; the overlap appears black). The $\operatorname{slp} 1$ stripes overlap the $w g$ stripes and extend 2 or 3 cells anterior. $(D) p t c^{I N}$ mutant stained as in $C$. The $w g$ stripe expands anteriorly to fill the $s l p$ domain (except for the ventral midline where $w g$ is not expressed; see arrowhead). $(E \mid$ Late stage 10 wild-type embryo stained with en protein (orange) and $\operatorname{slp} 1$ transcript (blue). (F) $n k d^{7 E}$ mutant stained as in $E$. en expression expands posteriorly to the border of the $s l p$ domain so that every cell in the ventral trunk stains orange or blue. The regions that do not appear to stain (see arrowhead) are cells out of the focal plane, due to the deep grooves that form in $n k d$ mutants.

al. 1991|. In slp mutants, the odd-numbered en stripes fade (Fig. 6A) and in $f t z$ mutants, the even-numbered ones are missing (Fig. 6B). In the double mutants, the odd-numbered stripes still decay (Fig. 6C). Therefore, in the absence of $f t z$ or eve activity, wg expression is still dependent on functional slp protein.

In constrast to the results with $f t z$ and $e v e$ described above, en activity was found to be partially responsible for the disappearance of $w g$ transcripts in slp mutants. At the time when the even-numbered PS wg stripes are completely gone in slp embryos (Fig. 6D), they are still present in slp, en double mutants (Fig. 6E). At early stage 10 , when the $w g$ stripes are completely gone in slp mutants, wg transcripts are still found in the double mutants (cf. Fig. 2H with Fig. 6F). However, much of the wg staining in the $s l p$, en mutants is not epidermal but, rather, is found in the underlying neuroblasts (Fig. 6F). Thus, wg expression in the epidermis is still dependent on $s l p$ in the absence of functional en protein. However, ectopic en expression does contribute to the disappear-

Figure 6. Distribution of $e$ transcripts $\mid A-$ $C)$ in $\operatorname{slp} ; f t z\left(\Delta 34 \mathrm{~B} ; f t z^{9 H}\right)$ mutants and $w g$ transcripts $(D-F)$ in $s l p$, en $\left(D f(2 L) e d^{S Z 1}\right.$, $D f(2 R)$ en- $E)$ mutants. $(A)$ en expression in a slp mutant, where the odd-numbered PS stripes fade (PS stripes 3,5 , and 7 are indicated). (B) en expression in a ftz embryo. The even-numbered PS stripes never arise. $(C)$ en expression in a slp; $f t z$ double mutant. The odd-numbered PS stripes fade as in $s l p \mathrm{mu}$ tants. $\{D \mid$ wg expression in a stage 9 slp embryo. The even-numbered stripes have com-
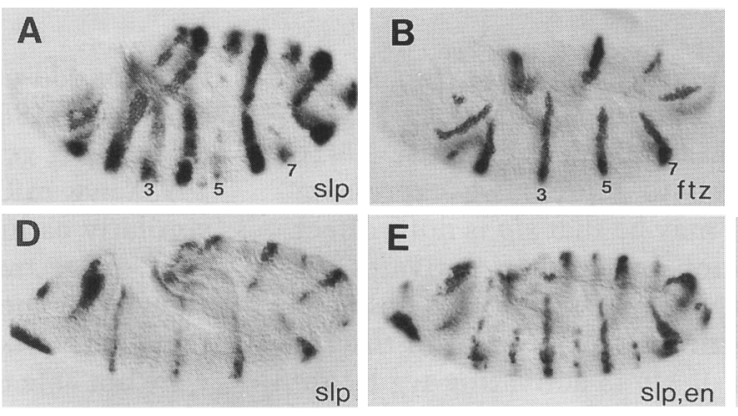
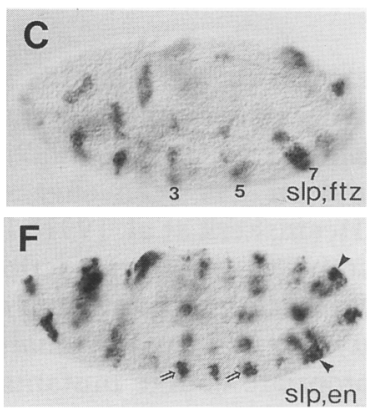

in a late stage $9 \mathrm{slp}$, en double mutant. Even though this embryo is older than the one shown in $D$, the even-numbered stripes, though faded, are still readily visible. (F) slp, en stage 10 embryo. In slp mutants, wg is completely gone from the trunk at this time (Fig. $2 \mathrm{H}$ ). In the double mutant, staining in the neuroblasts is still strong (open arrows), and some epidermal staining also remains (arrows). wg expression in these regions completely fades by early stage 11 . 
ance of $w g$ transcripts in slp mutants, most notably in the neuroblasts, and, to a lesser extent, in the epidermis.

In ptc mutants, the single-cell-wide wg stripes expand 2-3 cells anteriorly (Martinez-Arias et al. 1988; Ingham et al. 1991). Double staining for slp1 protein and wg transcripts in a ptc mutant reveals that $w g$ expands only to the border of slp expression (Fig. 5D), for example, every cell expressing $w g$ in the PS also expresses slp1 (and, by deduction, $\operatorname{slp} 2$, because it is expressed in the same cells as slp1). The width of the $\operatorname{sip}$ stripes does not change in ptc mutants. To determine whether slp is required for the ptc-dependent $w g$ expansion, we examined $w g$ expression in $s l p, p t c$ double mutants. As seen in Figure 7, $A$ and $C, w g$ expression fades in the double mutant just as it does in slp mutants, demonstrating that the ectopic expression of $w g$ in $p t c$ mutants requires $s l p$.

\section{en expression is restricted by overlapping slp and naked activities}

In naked (nkd) mutants, en expression expands posteriorly (DiNardo et al. 1988; Martinez Arias et al. 1988). When $n k d$ mutants are stained for $\operatorname{sip} 1$ transcripts and en protein (Fig. 5F) it was found that the en protein expanded just to the border of $s$ lp expression (the width of the $\operatorname{slp}$ stripes were unchanged in $n k d$ mutants), such that all cells in the ventral epidermis express either en or slp1 (but never both). This raised the possibility that $s l p$ limits the posterior expansion of en in nkd mutants. In $s l p ; n k d$ double mutants, en protein is found in almost all epidermal cells of the embryonic trunk (Fig. 7E, F). There are cells not expressing en, but these gaps are not segmental in periodicity, and several adjacent PSs can be found where all cells are en-positive. The simplest model would propose that within each PS, either slp or $n k d$ can repress $e n$ and that they have overlapping expression/ activity domains (see Fig. 10).

\section{Effect of ectopic slp protein on wg expression}

Experiments of Ingham et al. (1991) have led to a model for the regulation of $w g$ transcription during germ-band extension (see Fig. 10, below). The model predicts that the activity of ptc, a repressor of $w g$, is antagonized by $h h$, which is expressed in the en cells and is predicted to encode a surface protein that is processed into a secreted protein (Lee et al. 1992; Mohler and Vani 1992; Tabata et al. 1992; Taylor et al. 1993). The model, however, cannot explain why hh only activates the wg promoter on the anterior side of the $e n / h h$ cells. To reconcile this and explain the expression of $w g$ and en in ptc and nkd mutants, Ingham et al. (1991) proposed that only the cells in the posterior half of each PS are competent to express $w g$, whereas cells in the anterior half are en-competent.

The results presented so far in this paper suggest that the distribution of the slp proteins, which function as activators of $w g$ and repressors of en expression, may define these competence groups. If this were the case, then expression of $s 1 p$ in the anterior half of the PS should lead to ectopic wg expression there. Constructs were made in which either slp1- or slp2-coding sequences were placed under the control of a heat shock promoter and transgenic lines were created (see Materials and methods). A summary of the effect of ubiquitous expression of slp on $w g$ transcript distribution is shown in Figure 8.

The embryo in Figure 8A received its first heat shock at late syncitial blastoderm. This represents the most common class of phenotypes observed after heat shock at this time, with some embryos showing less wg transcript expansion and a few expressing wg almost everywhere in the trunk of the embryo. The expansion of the wg stripes in these embryos is probably attributable to ectopic slp protein repressing eve and, to a lesser extent, ftz (Cadigan et al. 1994). The wg expression pattern in
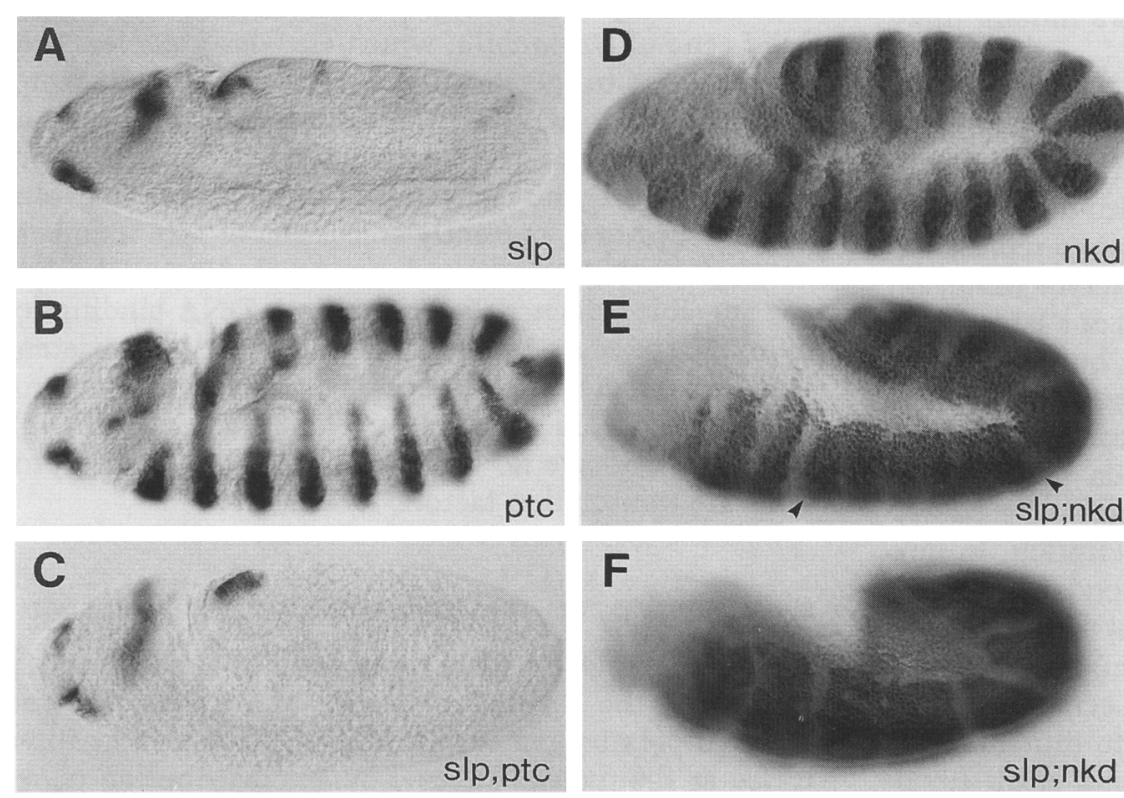

Figure 7. Expression of $w g$ transcripts (left) in slp, ptc $\left(D f(2 L) e d^{S Z 1}, p t c^{I N}\right)$ embryos and en protein (right) in slp; nkd $\left(\Delta 34 \mathrm{~B} ; n k d^{7 E}\right)$ embryos. $(A)$ slp embryo at stage 10. wg mRNA has faded from the trunk. $(B)$ ptc embryo at stage 10 . The characteristic wider $w g$ stripes are observed. $(C)$ slp, ptc double mutant at stage 10 . The expression of $w g$ in these mutants is identical to $s l p$ mutant embryos. $(D)$ nkd mutant at stage 10 displaying the broader en stripes. (E) sIp; nkd mutant at stage 10. Although not every cell in the trunk is expressing en, the arrows indicate a stretch of 6 PSs where virtually all epidermal cells are en-positive. $(F) s l p ; n k d$ mutant at stage 10 . As in $E$, several segments possess ubiquitous en expression. 

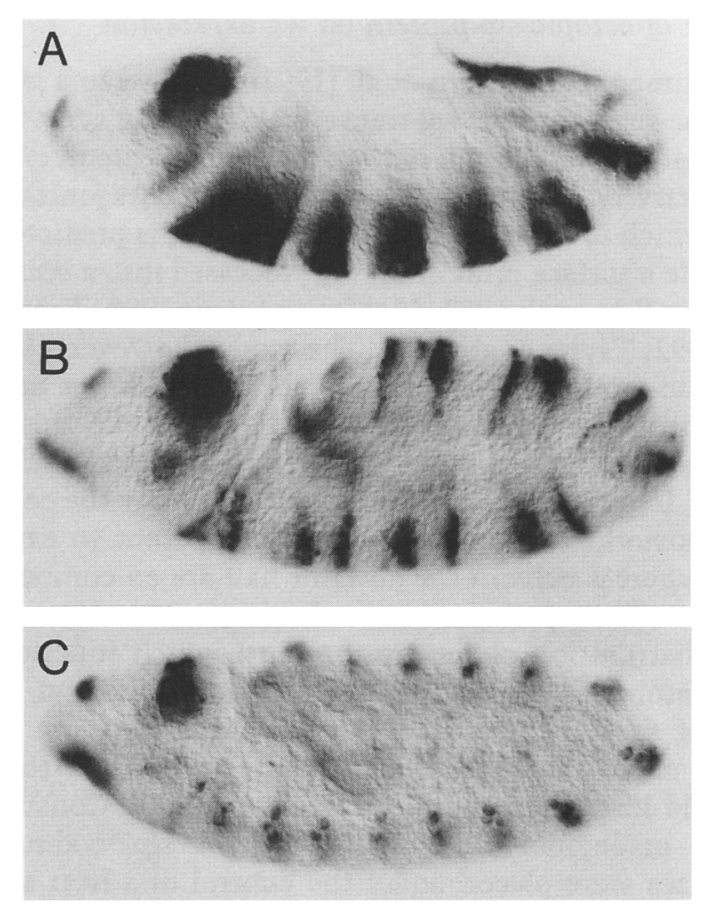

Figure 8. Expression of $w g$ transcripts after ubiquitious expression of slp1. $(A, B) \mathrm{P}[\mathrm{HS}-$ slp1C] embryos received two 5-min heat shocks (at $37^{\circ} \mathrm{C}$ ) separated by $55 \mathrm{~min}$ and were fixed $40 \mathrm{~min}$ after the second heat shock. The embryo shown in $A$ received its first heat shock at approximately late syncitial blastoderm. The wg stripes in this embryo are expanded, similar to what occurs in eve mutant embryos. The embryo in $B$ was first heatshocked at late cellular blastoderm. Spacing of the stripes is slightly irregular, and some ectopic expression is still observed. (C) This embryo was heat-shocked at approximately the same time as that in $B$ but was allowed to develop an additional 40 min before fixation. wg expression in the epidermis has faded, with only the neuroblast expression remaining.

Figure $8 \mathrm{~A}$ is very similar to that of an eve mutant (Ingham et al. 1988).

Heat shocks first administered after cellularization do not show this eve mutant-like expansion (Fig. 8B), and little ectopic wg expression is observed. If these embryos are allowed to develop, $w g$ mRNA fades from the epidermis (Fig. $8 \mathrm{C}$ ). This is probably attributable to repression of $h h$ and en expression in P[HS-slp] embryos [Cadigan et al. 1994/. If the heat shocks are applied at a later time, the fading of $w g$ transcripts is less severe, but ectopic $w g$ expression is never observed (data not shown).

Our hypothesis is that during germ-band extension, wg requires two inputs for its expression to be maintained properly: (1) hh protein to antagonize ptc activity, and (2) slp protein to activate $w g$ transcription. In our HS-slp experiments, providing the second input $|s l p|$ ubiquitously removes the first input $(h h)$ so that no ectopic wg expression can be induced. To circumvent this problem, we examined the effect of $s l p$ ectopic expression in a ptc mutant background. In ptc mutants, wg maintenance is independent of en (Tabata et al. 1992) and largely independent of $h h$ (Ingham et al. 1991; Bejsovec and Wieschaus 1993). The results of these experiments are shown in Figure 9.

Induction of $s l p$ protein in $p t c$ mutants caused a dramatic expansion of $w g$ transcripts (Fig. 9C-F) compared with non-heat-shocked controls (Fig. 9A, B). The heat shock regime was critical. One heat shock was not sufficient (even for $15 \mathrm{~min}$ ), and a 5-min heat shock followed by a 10 -min one (with $55 \mathrm{~min}$ recovery in between) gave the best results. If the first heat shock was administered after gastrulation, the expansion was limited. However, the heat shock could not be too early, or the expansion caused by eve repression would occur (see Fig. 8A). Therefore, the first heat shock was given between cellular blastoderm and gastrulation. Under these conditions, no ectopic wg expression was seen in P[HSslpl] embryos. In heat-shocked P[HS-slpl] ptc embryos, the expansion did not occur until late stage 9 (data not shown), the same time as ectopic wg expression occurs in ptc mutants (Ingham and Hidalgo 1993).

As seen in Figure 9, C and D, wg mRNA does not always fill the entire PS in P[HS-slp1] ptc mutants. To determine which cells are not expressing $w g$ in these embryos, we stained $\mathrm{P}[\mathrm{ftz}-\mathrm{lacC}]$; $\mathrm{P}[\mathrm{HS}-\mathrm{slp} 1]$, ptc embryos for $l a c Z$ protein and $w g$ transcripts after heat shock. P[ftz-lacC] expresses $l a c Z$ in a ftz-like manner, for example, the anterior border of $l a c Z$ marks the anterior border of the PS. This experiment demonstrated that the cells not expressing $w g$ lie in the anterior-most part of the PS (data not shown), where en is normally expressed.

\section{Discussion}

\section{The slp proteins are putative transcription factors}

The DNA sequence of the $\operatorname{sip} 1$ and $\operatorname{slp} 2$ transcription units (Grossniklaus et al. 1992) revealed an extensive region of homology that is now known as the forkhead domain (Weigel and Jäckle 1990), named after the forkhead gene of Drosophila, which encodes a nuclear protein involved in specification of fore- and hindgut structures (Weigel et al. 1989). This domain is also found in several hepatocyte DNA-binding transcription factors (Lai et al. 1991) and is conserved throughout the evolutionary spectrum, currently consisting of $>25$ members (Häcker et al. 1992; Clevidence et al. 1993). There is considerable evidence that it encodes a DNA-binding domain (Costa et al. 1989; Clark et al. 1993). Consistent with this predicted DNA-binding activity, the slp proteins are found in the nucleus (Fig. 5; data not shown). Although we have no direct evidence that the slp proteins are transciption factors, it is likely.

\section{slp has both a pair-rule and segment polarity function}

As described previously (Grossniklaus et al. 1992) and in this paper, the $\operatorname{slp}$ mutants have both a pair-rule and segment-polarity phenotype (Fig. 1). This is best illustrated at the molecular level by the distribution of $w g$ 

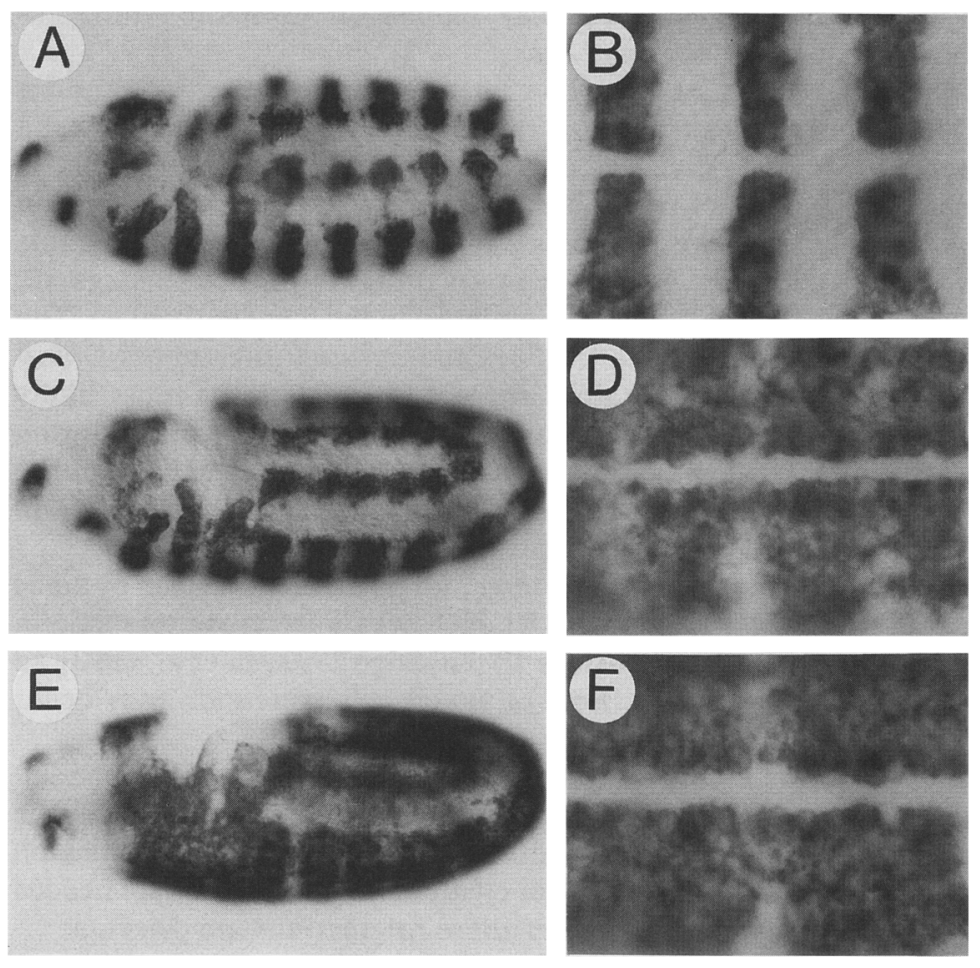

Figure 9. Expression of $w g$ transcripts after ubiquitous expression of slp1 in a ptc mutant background. $(A, B)$ Non-heat-shocked control showing the typical expression pattern of $w g$ in ptc embryos. $(C-F)$ p[HSslplC], $p t c^{P 78}$ embryos that were heat-shocked for 5 min, allowed to recover for $55 \mathrm{~min}$ before a $10-\mathrm{min}$ heat shock, and then fixed after $90 \mathrm{~min}$. The genotype of the embryos was concluded from the fact that $\mathrm{p}[\mathrm{HS}-\mathrm{slplC}$ (or any other P[HS-slp] line) never gave a similar phenotype under any conditions. Likewise, $p t c^{P 78}$ embryos heat-shocked as described showed no expansion of $w g$ expression. The embryo in $C$, which recieved its first heat shock at about the time of gastrulation, displays an intermediate phenotype, with a gap between wg domains in each PS. Experiments in which a $f t z-l a c Z$ chromosome (see Fig. 5G, H) was crossed into a $\mathrm{p}$ [HS-slp1C], ptc ${ }^{\mathrm{P} 78}$ background suggests that the anterior-most part of the PS (where en is normally found) is the area not expressing $w g$ in these intermediate-type embryos (data not shown). $D$ shows a high magnification shot of a similar aged embryo with a stronger phenotype, where each $w g$ domain has almost fused with each other. $E$ and $F$ show embryos slightly younger than those in $C$ and $D$ (first heat shock occuring at about late cellular blastoderm), both of which show the strongest phenotype observed (seen in more than half the ptc embryos at early stage 10). Here, some wg domains of adjacent PSs have completely fused. transcripts in $s l p$ mutants. The $w g$ stripes in the evennumbered PSs fade during germ-band extension (Fig. 2F). This leads to the decay of the adjacent en stripes (Fig. 2D), because they require $w g$ activity at this time (Bejsovec and Martinez Arias 1991; Heemskerk et al. 1991) so that only the even-numbered PS en stripes remain. The number of en stripes at this time is an accurate predictor of the number of segments that will form (DiNardo and O'Farrell 1987; Martinez-Arias and White 1988); hence, the fusion of segments seen in slp mutants. At full germband extension, the remaining wg stripes rapidly disappear (Fig. 2G). wg is known to be required at this time for the production of naked cuticle (Bejsovec and MartinezArias 1991). This correlates well with the lack of naked cuticle in slp mutants, similar to wg-class segment polarity mutants.

The disappearance of $w g$ in $s l p$ mutants occurs first in the even-numbered PS and then the odd-numbered, so one could imagine $s l p$ playing consecutive roles, first in one set of PS and then the other. However, we believe it is more accurate to propose that $s l p$ is required first in the even-numbered PSs and then in every PS for maintenance of $w g$ expression. This latter requirement in every PS can be demonstrated by comparing wg expression in double mutants of $p t c$ and the pair-rule gene prd with slp, ptc double mutants. At early stage 9 both look very similar (the even-numbered PS $w g$ stripes are gone). Shortly thereafter, however, the missing stripes arise in prd, ptc double mutant embryos (Ingham and Hidalgo 19931. This demonstrates that wg expression at this time does not require preexisting $w g$ and that the derepression seen in a ptc mutant background works independently of the earlier pair-rule regulation. In $s l p$, ptc mutants the missing even-numbered PS wg stripes do not return (Fig. $7 C)$, indicating that $s l p$ is required in these PSs for $w g$ expression at stage $9 / 10$. Thus, like other segment polarity genes, $s l p$ is required in every PS.

\section{Which genes are good candidates for direct targets of slp?}

A good candidate for direct regulation by slp should have an appropriate expression domain, and the misregulation seen in slp mutants should not be explainable by misexpression of other suspected regulators of the candidate. For example, even though the odd-numbered en stripes fade in slp mutants, en cannot be a direct target of $s l p$, as they are not expressed in the same cells. The effect of $s l p$ on en expression probably occurs through $w g$, which is known to be necessary for en maintenance at this time (Bejsovec and Martinez Arias 1991; Heemskerk et al. 1991). Thus, in slp embryos, wg transcripts in the evennumbered PSs fade, leading to the disappearance of the adjacent (odd-numbered PS) en stripes. The even-numbered PS en stripes in slp mutants remain, because en expression no longer requires $w g$ activity by the time the odd-numbered wg stripes fade (Bejsovec and Martinez Arias 1991; Heemskerk et al. 1991).

Because the $s l p$ proteins are expressed in the same cells as wg mRNA, it is possible that they act directly as positive regulators of $w g$ transcription. However, in $s l p$ mutants, $f t z$, eve, en, and $h h$ are ectopically expressed in 
the wg cells (Figs. 3 and 5). Three of these genes (ftz, eve, and $e n$ ) are thought to be repressors of $w g$, based on $w g$ distribution in $\mathrm{ftz}$ and eve mutants (Martinez-Arias and Ingham 1988) and heat shock experiments (Ish-Horowicz et al. 1989; Heemskerk et al. 1991; Manoukian and Krause 1992). This raises the possibility that slp activates $w g$ indirectly by repressing one or more of these $w g$ repressors. Analysis of $s l p$, eve or $s l p ; f t z$ double mutants did not reveal any such regulatory circuit (Fig. 6A-C; data not shown). Ectopic en expression was found to contribute to $w g$ transcript decay in slp mutants (Fig. 6D-F), but wg expression, especially in the epidermis, is still highly dependent on $s l p$ in the absence of functional $e n$. Perhaps the $f t z$, eve, and en proteins work together to inhibit wg expression in $s l p$ mutants, so that removing any one will not completely rescue $w g$ expression. This may be an explanation for the pair-rule decay of $w g$ expression in $s l p$ mutants during germ-band extension but cannot explain the subsequent decay of the remaining wg stripes because (1) ftz and eve are not present at detectable levels at that time, (2) in some genetic combinations of $s l p$ alleles that are not null, there is no ectopic expression of eve and en, but wg transcripts still fade (Cadigan et al. 1994), and (3) the expansion of wg seen in P[HS-slp1], ptc embryos after heat shock cannot be explained by repression of $f t z$ or $e v e$ expression and it can only partially be explained by repression of en (see below). Thus, although repression plays a significant role in the effect of $s l p$ on $w g$ expression, an activating function that may be direct must also be postulated.

In slp mutant embryos, $f t z$, eve, en, and $h h$ are all ectopically expressed in cells normally containing slp. Because none of the other pair-rule genes are affected by $s l p$ in a segmental fashion, $s l p$ may regulate $f t z$ and $e v e$ transcription directly. Consistent with this, ectopic expression of either $s 1 p$ protein can repress expression of these genes (Cadigan et al. 1994).

At cellular blastoderm, eve and $f t z$ are both thought to be positive regulators of $e$ expression (MacDonald et al. 1986; DiNardo and O'Farrell 1987; Martinez-Arias and White 1988). Does the anterior expansion of $e n$ stripes in slp mutants depend on $f t z$ and eve? We consider this unlikely for the following reasons. First, when the en stripes start to expand (late stage 8), the levels of eve and $\mathrm{ftz}$ proteins are rapidly falling. Embryos can be found in which expanded odd-numbered PS en stripes coincide with eve protein expression (Fig. 4C, D). However, the time window between onset of en stripe widening and eve disappearance is extremely brief. The even-numbered PS en stripes expand slightly later than the oddnumbered ones (see Fig. 4C), and we were unable to see significant amounts of $f t z$ protein by the time the evennumbered en stripes were noticeably wider (data not shown). The second line of evidence minimizing the importance of $e v e$ and $f t z$ in the regulation of en expression by $s l p$ is that P[HS-slp] embryos in which the first heat shock is administered at mid-stage 9 (when $f t z$ and $e v e$ have faded) show a complete lack of en transcripts (Cadigan et al. 1994). In summary, although we cannot rule out (especially for $e v e$ ) the role of the two pair-rule genes in en expansion in slp mutants, the evidence seems to indicate that $s l p$ may repress en expression independently of $f t z$ and eve.

The pattern of $h$ h expression in $s l p$ mutants is similar to that of en (Fig. 3B) and P[HS-slp] embryos lack $h h$ transcripts after induction (Cadigan et al. 1994). hh is regulated by all other segmentation genes in a fashion identical to en (Lee et al. 1992; Tabata et al. 1992) but is expressed normally in en mutants until late stage 10 . Thus, $s l p$ probably regulates $h h$ independently of $e n$. The patterns of ptc (Fig. 3F) and cubitus interruptus Dominant $\left(\mathrm{ci}^{D}\right.$; data not shown) in $\operatorname{slp}$ mutants most likely occur because of altered distribution of the transcription factor en, because en is known to be a repressor of the expression of these genes (Eaton and Kornberg 1990; Hidalgo and Ingham 1990).

Another possible target for positive regulation by slp is the $g s b$ gene (Fig. 3D). However, gsb transcripts fade in wg mutants at stage 10 (Hildalgo 1991; Li et al. 1993), so the positive effects of $s l p$ on $g s b$ expression may occur through wg.

In summary, $f t z$, eve, en, and $h h$ are all good candidtates for being directly repressed by $s l p$, and $w g$ is the best candidate for direct activation. Further studies on the cis-acting control elements of these genes are needed to ascertain whether these interactions are direct.

\section{slp maintains the polarity of the PS}

After $w g$ transcription is initiated by the pair-rule genes, a signal from the adjacent $e n$-expressing cells is needed for maintainence of $w g$ expression. This signal is thought to be the $h$ h gene product, which is processed to form a secreted protein (Lee et al. 1992; Taylor et al. 1993). In the absence of $h h$, wg transcripts are completely gone at early stage 10 (Ingham and Hildalgo 1993), attributable to the repressing activity of ptc (Ingham et al. 1991), an integral membrane protein found at the cell surface (Hooper and Scott 1989; Nakano et al. 1989). The hh protein is thought to somehow interfere with ptc activity, so that wg expression is maintained in the cells just anterior of the en-expressing cells (see Fig. 10 for diagram). The question remains as to why $h h$ does not activate $w g$ transcription in the cells posterior of the en cells, because $h h$ is known to be required for maintenance of $p t c$ expression in these cells (Hidalgo and Ingham 1990; Forbes et al. 1993) indicating that $h h$ can act symmetrically.

To explain the different responses of the cells on each side of the en stripes, Ingham et al. (1991) proposed that PSs are divided into $w g$ - and en-competent domains. The $w g$-competent group are cells that express $w g$ in $p t c \mathrm{mu}$ tants; the en-competent group are cells expressing en in $n k d$ mutants. The $s l p$ expression domain coincides with the $w g$-competent cells (Fig. 5D). Furthermore, all of the cells expressing $w g$ in a ptc mutant background require functional slp for this expression (Fig. 7A-C). These data are consistent with the idea that the wg-competent group is determined by the presence of $s l p$ protein.

If the presence of $s l p$ protein does determine a cell to 

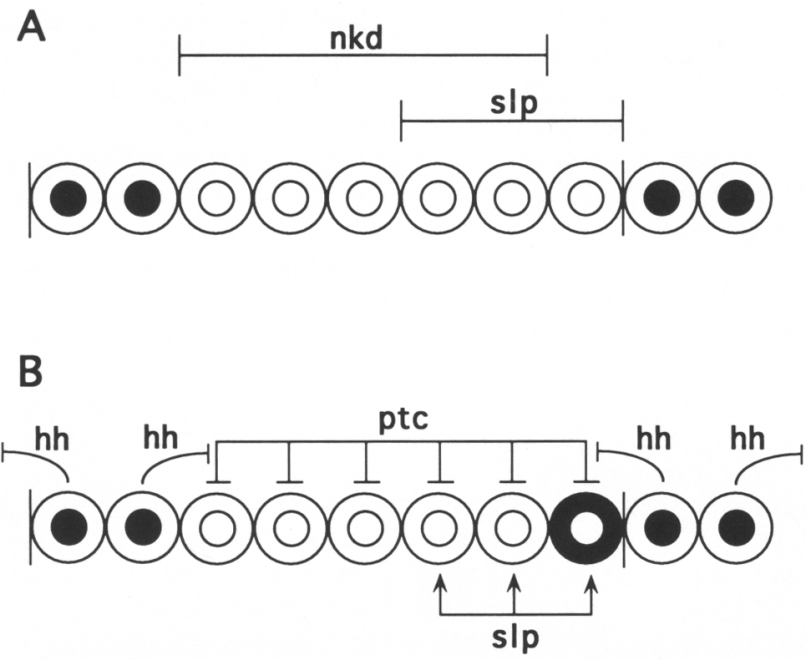

Figure 10. Summary of slp action on en and wg expression. $(A)$ PSs are shown eight cells wide (vertical lines denote the location of the parasegmental grooves), with dark nuclei representing the normal expression domain of en. We postulate overlapping repressing activities of $s l p$ and $n k d$ on en expression. In $s l p$ mutants, the en stripes expand $\sim 1$ cell anteriorly (Fig. $4 E-H$ ). In $n k d$ mutants, they expand posteriorly to the anterior border of the $s l p$ expression domain (Fig. 5F). In $s l p ; n k d$ double mutants, virtually every cell in the PS expresses en (Fig. $7 E, F)$. These data are consistent with a model in which either $\operatorname{slp}$ or $n k d$ activity is enough to repress $e n$ and predicts that $n k d$, which is not yet cloned, will be expressed in the broad domain indicated (or at least have activity in these cells). (B) Incorporation of $s$ lp into the model of Ingham et al. (1991). en is represented by the darkened nuclei and $w g$ as the darkened cytoplasm. See text for further explanation.

be wg-competent, then expression of $s l p$ on the posterior side of the en stripes (via the heat shock promoter) should result in wg expression there. However, ectopic slp protein abolishes $h$ h expression (Cadigan et al. 1994), so that no ectopic $w g$ transcripts were observed (Fig. 8). Because $w g$ expression is independent (at least in large part) of hh in ptc mutants (Ingham et al. 1991; Bejsovec and Wieschaus 19931, we examined the distribution of $w g$ in P[HS-slp], ptc embryos after heat shock (Fig. 9). Consistent with our proposed role for $s l p$, we found that $w g$ was expressed almost throughout the PS after heat shock. The few cells that do not express $w g$ are within the normal en domain. The reluctance of these cells to express wg may be attributable to the ability of en to repress wg expression (Fig. 6D-F; Heemskerk et al. 1991), though en expression is repressed after heat shock induction of $s l p$ under the conditions used in Figure 9 (data not shown). It may be that cells previously expressing en for a certain time are subsequently not competent for $w g$ expression later, despite the absence at that time of en. Consistent with this is the observation that the $\mathrm{P}[\mathrm{HS}-\mathrm{slp}], p t c$ embryos not expressing $w g$ in the en domain in general were older at the time of first heat shock than embryos expressing $w g$ throughout (see Fig. 9).

Because of its ability to repress en (see next section) and activate $w g$, the competence groups proposed by Ingham et al. (1991) can be explained entirely by the distribution of $s l p$ protein in the PS. slp is not required for the initiation of the $w g$ and en stripes at cellular blastoderm, but localized $s 1 p$ expression is needed to maintain the polarized distribution of $w g$ and en transcripts during germ-band extension. slp can be viewed as the benchmark on which segment polarity is maintained.

\section{Repression and regulation of en}

Drosophila segments are divided into two compartments, each with a distinct cell lineage (Lawrence 1981). en is is expressed in the posterior compartments of embryo and larval segments (Kornberg et al. 1985) and is thought to play an active role in maintaining the lineage boundary between the compartments (Lawrence and Morata 1976; Kornberg 1981). Thus, the regulation of en expression has been studied extensively as a model for the establishment of a determined cell state (Heemskerk et al. 1991; Bienz 1992). In embryos mutant for either slp or $n k d$, the expression of en is initiated normally, but the en stripes widen during germ-band elongation, in an anterior direction in slp mutants (Fig. 4), and a posterior one in $n k d$ mutants (Fig. 5F, DiNardo et al. 1988; Martinez Arias et al. 1988). The amount of en expansion in $s l p ; n k d$ double mutants is more than the sum of the single phenotypes, that is, almost all the epidermal cells in each segment are en positive (Fig. 7D-F), suggesting that $s l p$ and $n k d$ have overlapping repressing activities (Fig. 10). The activity of pair-rule repressors (i.e., run, $e v e$, and odd) is also thought to be important in the initiation of the en stripes at cellular blastoderm (Manoukian and Krause 1993) and genes of the Polycomb group repress en during germ-band shortening (Moazed and O'Farrell 1992). It is interesting to note that in studies on the regulation of another cell fate determinator, Ultrabithorax, repression is also thought to play a critical role, first involving the gap gene hunchback and then genes of the Polycomb class (Bienz 1992).

The elegant study of Vincent and O'Farrell (1992) demonstrated that the expression domain of en does not expand clonally in early embryos, that is, some daughters of en-positive cells no longer express $e n$. However, they did find a strict lineage boundary at the anterior border of en stripes, which is where the parasegmental grooves form (Ingham et al. 1985a) and which is thought to mark the anterior extent of the posterior compartment (Lawrence and Martinez-Arias 1985). In slp mutants, both the anterior border of $e$ and the location of the parasegmental grooves are shifted anteriorly (Fig. 4I). It remains to be seen whether the cells ectopically expressing en in $s l p$ mutants are derived from en-positive cells or from cells that have never previously expressed $e$.

\section{A possible role for slp in the $\mathrm{hh} / \mathrm{ptc}$ signal transduction pathway}

As summarized above, $p t c$ activity represses wg transcription, and $h$ h somehow interferes with this repres- 
sion. Both genes encode proteins that are thought to act at the cell surface. The genes fused $(f u)$ and $c i^{D}$ also are required for maintenance of $\mathrm{wg}$ expression during germband extension, and genetic evidence indicates they are required in the wg-expressing cell, suggesting that they act in the $h h / p t c$ signaling pathway (Forbes et al. 1993; Ingham 1993). $f u$ is predicted to encode a serine-threonine kinase expressed throughout the embryo (Preat et al. 1990), and $c i^{D}$ is a zinc finger protein expressed in all the cells not expressing en (Eaton and Kornberg 1990; Orenic et al. 1990). The $s l p$ proteins are required for $w g$ expression at the same time as $p t c, h h$, fus, and $c i^{D}$, raising the possibility that $s l p$ is a nuclear recipient of the $h h / p t c$ signal.

Alternatively, slp may not be part of the signaling pathway but may act in parallel with it. This hypothesis is supported by the comparsion of the regulation of $w g$ and ptc expression. Both are repressed by ptc activity which, in turn, is antagonized by $h h$. Moreover, $f u$ and $c i^{D}$ are also required for the maintenance of $w g$ and $p t c$ (Forbes et al. 1993). In constrast, slp is not required for ptc maintenance (Fig. 3E, F). Therefore, the simplest model incorporating the available data would predict that $h h, p t c, f u$, and $c i^{D}$ are part of a signaling pathway regulating $w g$ and $p t c$ transcription. This pathway functions both anterior and posterior of the en/hh expression domain, but wg expression, in constrast to that of ptc, is only activated on the anterior side, because it has an absolute requirement for slp protein. Thus, the asymmetric distribution of $s l p$ protein within each PS leads to the polarized response of the wg promoter to the $h h / p t c$ signal. Further biochemical studies of the $\operatorname{sip}$ proteins, as well as detailed analysis of the $w g$ promoter for $s l p$-binding sites, will be necessary to further elucidate the function of $s l p$ in $w g$ regulation and its relationship to the other gene products required for wg expression.

\section{Materials and methods}

\section{Fly stocks}

The $s l p$ deficiencies $D f(2 L) e d^{S Z 1}$ and $C y O \triangle 34 \mathrm{~B}$ (hereafter referred to as $\triangle 34 \mathrm{~B}$ ), as well as the enhancer trap insert (CyO $\mathrm{P}[\mathrm{LArB}] \mathrm{A} 208.1 \mathrm{M} 2$ ) from which $\triangle 34 \mathrm{~B}$ was derived, are described in Grossniklaus et al. (1992). CyO P[larB|A208.1M2 homozygotes do not hatch, but their cuticles and the expression of en and $w g$ were all identical to wild-type embryos /data not shown). $\triangle 34 \mathrm{~B}$ and $D f(2 L) e d^{S Z 1}$ homozygotes and $\triangle 34 \mathrm{~B} /$ $D f(2 L) e d^{S Z 1}$ transheterozygotes all displayed similar misregulation of $e n$ and $w g$ expression (Figs. 2, 6, and 7; data not shown), though $D f(2 L) e d^{S Z 1}$ embryos begin to exhibit gross abnormalities not linked to $s l p$ during germ-band retraction.

$\mathrm{P}[\mathrm{ftz}-\mathrm{lacC}]$ contains $6.0 \mathrm{~kb}$ of the $f t z$ promoter, enhancer and translation start site sequences fused to lacZ (Hiromi et al. 1985). A first chromosome insertion strain was used for creating a P[ftz-lacZ]; $b$ Adh cn l(2)/ $\triangle 34 \mathrm{~B}$ stock. Other mutant alleles used were $e v e^{R 13}, p t c^{I N}, p t c^{P 78}, n k d^{7 E}, D f(2 R) e n-E, e n^{I O}$ and $f t z^{9 H} . D f(2 R) e n-E$ is a small deficiency removing both $e n$ and invected ( $\mathrm{Z}$. Ali and T. Kornberg, pers. comm.). The eve $e^{R 13}$ allele is an amorph (Nüsslein-Volhard et al. 1984). ptc ${ }^{P 78}$ (Nakano et al. 1989) and $\mathrm{ftz}^{9 \mathrm{H}}$ (Furukubo-Tokunaga et al. 1992) are nulls; $p t c^{I N}$ gave similar results as $p t c^{P 78}$, and the $e n^{I O}$ and $n k d^{7 E}$ alleles are classified as strong (Tearle and Nüsslein-Volhard 1987). To examine embryos mutant for slp (on the second chromosome), and either $f t z$ or $n k d$ (both on the third), slp flies were crossed to either allele (balanced by TM3, $S b$ ) and $C y$, non- $S b$ progeny were mated and embryos collected. In both cases, mutant phenotypes segregated in close to the theoretical 9:3:3:1 ratios. Chromosomes containing $D f(2 L) e d^{S Z 1}$ and either $p t c^{I N}$, $e v e^{R 13}, e n^{I O}$, or $D f(2 R) e n-E$ were created by recombination. Complementation tests (and in the case of the deficiencies, in situ hybridization with slp or en probes/ were performed to confirm the genotypes.

\section{Heat shock slp flies and cuticle preparations}

A brief description of the cloning of heat shock slp constructs is given below. A detailed protocol is available upon request. Oligonucleotide primers hybridizing just $5^{\prime}$ and $3^{\prime}$ of the $\operatorname{slp} 1$ and slp2 open reading frames (ORFs) were used to amplify the slpcoding regions from genomic phages (neither slp gene has introns; Grossniklaus et al. 1992) with the polymerase chain reaction (PCR) (Saiki et al. 1985) and to introduce restriction sites to facilitate subsequent cloning. Products of two separate reactions for $\operatorname{slp} 1$ and one for slp2 were cloned into pBluescript. The ORFs were then cloned into pNHT4, a P-element vector containing the $5^{\prime} h s p 70$ promoter and $3^{\prime}$ termination sequences (Gibson et al. 1990). rosy ${ }^{506}$ embryos were coinjected with the P-element heat shock sip (P[HS-slp]| constructs and $\mathrm{p} \pi 25.7$ as described previously (Rubin and Spradling 1982; Karess and Rubin 1984) and several independent transgenic lines for each construct were established. Examination of cuticle phenotypes after heat shocks during early embryogenesis, which is described in detail elsewhere (Cadigan et al. 1994), showed a qualitatively similar result with all lines, although the strength of the phenotype varied from line to line. The lines selected for further study lones that produced the strongest and most consistent phenotype) expressed high levels of the respective slp transcript and protein after heat shock, as judged by whole mount in situ hybridization or immunostaining. A strong $\operatorname{sip} 1$ heat shock construct on the second chromosome, P[HS-slp1C], was recombined with the $p t c^{P 78}$ mutation for the experiments described in Figure 9.

Heat shocks were performed in the following way. Embryos were collected on grape juice plates for a short time (40-60 min) and aged at $25^{\circ} \mathrm{C}$. Shortly before heat shock, they were dechlorinated with bleach and collected on a nylon mesh. This mesh was placed on a moist piece of Whatman paper in a petri dish. This dish was sealed by parafilm and submerged in a $37^{\circ} \mathrm{C}$ bath (usually for $5 \mathrm{~min}$ ), and the embryos were allowed to recover at $25^{\circ} \mathrm{C}$ before a second heat shock and subsequent fixation or analysis of cuticle. The time when the first heat shock was administered was approximated by extrapolating back from the age of the individual fixed embryos and a knowledge of the rate of development under our culture conditions.

Cuticles were prepared essentially as described by NüssleinVolhard et al. (1984) except that the vitelline membranes were removed by vigorous agitation in methanol/heptane (1:1). The embryos were then transferred to a slide, and the remaining solvent was allowed to evaporate before covering with Hoyer's medium/lactic acid $(1: 1)$.

\section{Antibody production and immunostaining}

Escherichia coli-expressed protein was the source of $\operatorname{slp1}$ antigen for immunization. The slp1 PCR products described above were cloned into $\mathrm{pET}-3 \mathrm{~d}$, an E. coli T7 expression vector (Studier et al. 1990). Protein from a SDS gel was transferred to a 
nitrocellulose filter. After staining with Ponceau $\mathrm{S}(0.4 \%$ in $3 \%$ trichloroacetic acid), the $\operatorname{slp} 1$ band was cut out, the Ponceau $S$ was washed away with PBS containing $0.3 \%$ Triton-X100, and the filter dried in an oven overnight. The filter was dissolved in dimethylsulfoxide (DMSO) as described by Knudsen (1985) and mixed with Freund's adjuvant $(1: 2)$ before immunization. The slp2 antigen was a fusion protein consisting of glutathione $S$-transferase linked to the carboxy-terminal third (amino acids 295-445) of slp2. The slp2 DNA fragment was a PCR fragment described in Grossniklaus et al (1992) cloned into pGEX-2T. The fusion protein was produced and purified as described (Smith and Johnson 1988). Rats were immunizied by dermal injection, first with $50 \mu \mathrm{g}$ antigen emulsified with complete Freund's adjuvant, and then boosted every 4 weeks with antigen/incomplete adjuvant. Animals were terminally bled 10 days after the third or fourth boost.

Antibody stainings were performed essentially as described by Frasch et al. (1987) and Grossniklaus et al. (1992). The rabbit polyclonal anti-eve (Frasch et al. 1987) and anti-ftz (Krause et al. 1988) antisera were gifts of M. Frasch (Mount Sinai Medical Center, NY) and H. Krause (Toronto University, Canada). The mouse monoclonal anti-en antibody (Patel et al. 1989) was a gift from C. Goodman (University of California at Berkeley) and N. Patel (Carnegie Institute, Baltimore, MD). The rabbit anti-lacZ polyclonal antisera was from Cappel. The primary antibodies were used at the following dilutions: en, 1:1; slp2 and $f t z, 1: 200$; slp1, 1:300, lacZ, 1:1000 and eve, 1:2000. The secondary antibodies were either biotinylated (goat anti-mouse, horse antirabbit and rabbit anti-rat; all from the Elite $\mathrm{ABC}$ kit, Vectastain, used at a 1:500 dilution) or alkaline phosphatase conjugated (swine anti-rabbit from Dakopatts and goat anti-rat from Orgarion Teknika Corp.; both were used at a 1:200 dilution).

\section{Analysis of transcript distribution}

In situ hybridization to whole-mount embryos using digoxygenin-labeled probes was performed according to Tautz and Pfeifle (1989), with modifications (a detailed protocol is available on request). The en cDNA pF7036 (Fiose et al. 1985) was used for the en probe. The other DNA templates were all cDNAs and were generous gifts from the following sources: $w g, p B S-C V$ (Rijsewijk et al. 1987) from M. van den Heuvel and R. Nusse (Stanford University, CA); prd, c7340.6 (Kilcherr et al. 1986) and gsb, BSH9c2 (Baumgartner et al. 1987) from M. Noll (University of Zurich, Switzerland); $h h$, chh46 (Tabata et al. 1992) from S. Tabata and T. Kornberg (University of California at San Francisco); ptc, pGEM7-ptc (Hooper et al. 1989) from Y. Higashi and M. Scott (Stanford University, CA); $\mathrm{Ci}^{D}$, cDNA9-11 (Orenic et al. 1990) from D. Slusarski and R. Holmgren (Northwestern University, IL); odd (cDNA clone A; Coulter et al. 1990) from D. Coulter (Washington University, MI); $h$, D2P8 (Ish-Horowitz et al. 1985) from D. Ish-Horowicz (University of Oxford, UK) and run, pBED-5' (Kania et al. 1990) from M. Klingler and P. Gergen (State University of New York at Stony Brook, NY).

\section{Acknowledgments}

We thank all the researchers who generously supplied the fly stocks and the cDNAs listed in Materials and methods. Special thanks to Roel Nusse, in whose laboratory the final experiments for this paper were performed; this work could not have been presented in its current form without his generous support. We acknowledge all the stimulating discussions and advice from members of the Gehring and Nusse laboratory, notably Marcus Affolter, Alex Schier, Jasprien Noordemeer, Derek
Lessing, and especially Georg Halder, who suggested the P[HSslp], ptc experiments. We also thank Jasprien Noordemeer, Derek Lessing, Georg Halder, Diane Spillane, Matthew Scott and Roel Nusse for critical reading of the manuscript and Derek Lessing for help in preparing Figure 10. This work was supported by an American Cancer Society fellowship to K.M.C., a fellowship of the Stipendienfonds der Basler Chemischen Industrie to U.G., the Swiss National Science Foundation, and the Kantons of Basel-Stadt and Basel Landschaft.

The publication costs of this article were defrayed in part by payment of page charges. This article must therefore be hereby marked "advertisement" in accordance with 18 USC section 1734 solely to indicate this fact.

\section{References}

Akam, M. 1987. The molecular basis for metameric pattern in the Drosophila embryo. Development 101: 1-22.

Baker, N.E. 1987. Molecular cloning of sequences from wing less, a segment polarity gene in Drosophila: The spatial distribution of a transcript in embryos. EMBO I. 6: 1765-1773.

. 1988. Embryonic and imaginal requirements for wingless, a segment-polarity gene in Drosophila. Dev. Biol. 125: 96-108.

Baumgartner, S. and M. Noll. 1991. Network of interactions among pair-rule genes regulating paired expression during primordial segmentation of Drosophila. Mech. Dev. 33: 118.

Baumgartner, S., D. Bopp, M. Burri, and M. Noll. 1987. Structure of two genes at the gooseberry locus related to the paired gene and their spatial expression during Drosophila embryogenesis. Genes \& Dev. 1: 1247-1267.

Bejsovec, A. and A. Martinez Arias. 1991. Roles of wingless in patterning the larval epidermis of Drosophila. Development 113: 471-485.

Bejsovec, A. and E. Wieschaus. 1993. Segment polarity gene interactions modulate epidermal patterning in Drosophila embryos. Development 119: 501-517.

Bienz, M. 1992. Molecular mechanisms of determination in Drosophila. Curr. Opin. Cell Biol. 4: 955-961.

Cadigan, K.M., U. Grossniklaus, and W.J. Gehring. 1994. Functional redundancy: The respective roles of the sloppy paired proteins in segmentation. Proc. Natl. Acad. Sci. (in press).

Campos-Ortega, J.A. and V. Hartenstein. 1985. The embryonic development of Drosophila melanogaster. Springer-Verlag, Berlin, Germany.

Clark, K.L., E.D. Halay, E. Lai, and S.K. Burley. 1993. Co-crystal structure of the HNF-3/fork head DNA-recognition motif resembles histone H5. Nature 364: 412-420.

Clevidence, D.E., D.G. Overdier, W. Tao, X. Qian, L. Pani, E. Lai, and R.H. Costa. 1993. Identification of nine tissue-specific transcription factors of the hepatocyte nuclear factor 3/forkhead DNA-binding domain family. Proc. Natl. Acad. Sci. 90: 3948-3952.

Costa, R.H., D.R. Grayson, and J.E. Darnell. 1989. Multiple hepatocyte-enriched nuclear factors function in the regulation of transthyretin and al-antitrypsin genes. Mol. Cell. Biol. 9: 1415-1425.

Coulter, D.E., E.A. Swaykus, M. Beran-Koehn, D. Goldberg, E. Wieschaus, and P. Sched1. 1990. Molecular analysis of oddskipped, a zinc finger encoding segmentation gene with a novel pair-rule expression pattern. EMBO J. 9: 3795-3804.

DiNardo, S. and P.H. O'Farrell. 1987. Establishment and refinement of segmental pattern in the Drosophila embryo: Spatial control of engrailed expression by pair-rule genes. Genes 
\& Dev, 1: 1212-1225.

DiNardo, S., J.M. Kuner, J. Theis, and P.H. O'Farrell. 1985. Development of embryonic pattern in $\mathrm{D}$. melanogaster as revealed by accumulation of the nuclear engrailed protein. Cell 43: 59-69.

DiNardo, S., E. Sher, J.J. Heemskerk, J.A. Kassis, and P.H. O'Farrell. 1988. Two-tiered regulation of spatially patterned engrailed gene expression during Drosophila embryogenesis. Nature 332: 604-609.

Eaton, S. and T. Kornberg. 1990. Repression of $c i-D$ in posterior compartments of Drosophila by engrailed. Genes \& Dev. 4: 1068-1077.

Fjose, A., W.J. McGinnis, and W.J. Gehring. 1985. Isolation of a homeobox containing gene form the engrailed region of Drosophila and the spatial distribution of its transcripts. $\mathrm{Na}$ ture 313: 284-289.

Forbes, A.J., Y. Nakano, A.M. Taylor, and P.W. Ingham. 1993. Genetic analysis of hedgehog signaling in the Drosophila embryo. Development (Suppl.) 119 (in press).

Frasch, M., T. Hoey, C. Rushlow, H. Doyle, and M. Levine. 1987. Characterization and localization of the even-skipped protein of Drosophila. EMBO 1. 6: 749-759.

Furukubo-Tokunaga, K., M. Muller, M. Affolter, L. Pick, U. Kloter, and W.J. Gehring. 1992. In vivo analysis of the helixturn-helix motif of the fushi tarazu homeo domain of Drosophila melanogaster. Genes \& Dev. 6: 1082-1096.

Gibson, G., A. Schier, P. LeMotte, and W.J. Gehring. 1990. The specificities of Sex comb reduced and Antennapedia are defined by a distinct portion of each protein that includes the homeo domain. Cell 62: 1087-1103.

Gonzalez, F., L. Swales, A. Bejsovec, H. Skaer, and A. MartinezArias. 1991. Secretion and movement of wingless protein in the epidermis of the Drosophila embryo. Mech. Dev. 35: 4354

Grossniklaus, U., R. Kurth-Pearson, and W.J. Gehring. 1992. The Drosophila sloppy paired locus encodes two proteins involved in segmentation that show homology to mammalian transcription factors. Genes \& Dev. 6: 1030-1051.

Gutjahr, T., N.H. Patel, X. Li, C.S. Goodman and M. Noll. 1993. Analysis of the gooseberry locus in Drosophila embryos: gooseberry determines the cuticular pattern and activates gooseberry neuro. Development 118: 21-31.

Häcker, U., U. Grossniklaus, W.J. Gehring, and H. Jäckle. 1992. Developmentally regulated Drosophila gene family encoding the fork head domain. Proc. Natl. Acad. Sci. 89: 87548758 .

Heemskerk, J., S. DiNardo, R. Kostriken, and P.H. O'Farrell. 1991. Multiple modes of engrailed regulation in the progression towards cell fate determination. Nature 352: 404-410.

Hidalgo, A. 1991. Interactions between segment polarity genes and the generation of the segmental pattern in Drosophila. Mech. Dev. 35: 77-87.

Hidalgo, A. and P. Ingham. 1990. Cell patterning in the Drosophila segment: Spatial regulation of the segment polarity gene patched. Development 110: 291-301.

Hiromi, Y., Kuroiwa, A., and W.J. Gehring. 1985. Control elements of the Drosophila segmentation gene fushi tarazu. Cell 43: 603-613.

Hooper, J.E. and M.P. Scott. 1989. The Drosophila patched gene encodes a putative membrane protein required for segmental patterning. Cell 59: 751-765.

- 1992. The molcular genetic basis of positional information in insect segments. In Results and problems in cell differentiation (ed. W. Hennig), pp. 1-48. Springer-Verlag, Berlin/Heidelberg 1992, Germany.

Ingham, P.W. 1988. The molecular genetics of embryonic pat- tern formation in Drosophila. Nature 335: 25-34.

1993. Localized hedgehog activity controls spatial limits of wingless transcription in the Drosophila embryo. $\mathrm{Na}$ ture 366: 560-562.

Ingham, P.W. and A. Hidalgo. 1993. Regulation of wingless transcription in the Drosophila embryo. Development 117: 283291.

Ingham, P.W., A. Martinez-Arias, P.A. Lawrence, and K. Howard. 1985a. Expression of engrailed in the parasegment of Drosophila. Nature 317: 634-636.

Ingham, P.W., K.R. Howard, and D. Ish-Horowicz. 1985b. Transcription pattern of the Drosophila segmentation gene hairy. Nature 318: 439-445.

Ingham, P.W., N.E. Baker, and A. Martinez-Arias. 1988. Regulation of segment polarity genes in the Drosophila blastoderm by fushi tarazu and even skipped. Nature 331: 73-75.

Ingham, P.W., A.M. Taylor, and Y. Nakano. 1991. Role of the Drosophila patched gene in positional signaling. Nature 353: 184-188.

Ish-Horowicz, D., K.R. Howard, S.M. Pinchin, and P.W. Ingham. 1985. Molecular and genetic analysis of the hairy locus in Drosophila. Cold Spring Harbor Symp. Quant. Biol. 50: 135-144.

Ish-Horowicz, D., S. Pinchin, P.W. Ingham, and P. Gyurkovics. 1989. Autocatalytic $f t z$ activation and metameric instability by ectopic $f t z$ expression. Cell 57: 223-232.

Kania, M.A., A.S. Bonner, J.B. Duffy, and J.P. Gergen. 1990. The Drosophila segmentation gene runt encodes a novel nuclear regulatory protein that is also expressed in the developing nervous system. Genes \& Dev. 4: 1701-1713.

Karess, R.E., and G.M. Rubin. 1984. Analysis of P transposable element functions in Drosophila. Cell 38: 135-146.

Kilchherr, F., S. Baumgartner, D. Bopp, E. Frei, and M. Noll. 1986. Isolation of the paired gene of Drosophila and its spatial expression during early embryogenesis. Nature 321: 493-499.

Kornberg, T. 1981. Engrailed: A gene controlling compartment and segment formation in Drosophila. Proc. Natl. Acad. Sci. 78: 1095-1099.

Kornberg, T., I. Siden, P. O'Farrell, and M. Simon. 1985. The engrailed locus of Drosophila: In situ localization of transcripts reveals compartment-specific expression. Cell 40: $45-53$.

Knudsen, K.A. 1985. Proteins transferred to nitrocellulose for use as immunogens. Anal. Biochem. 147: 285-288.

Krause, H.M., R. Klemenz, and W.J. Gehring. 1988. Expression, modification, and localization of the fushi tarazu protein in Drosophila embryos. Genes \& Dev. 2: 1021-1036.

Lai, E., V.R. Prezioso, W. Tao, W.S. Chen, and J.E. Darnell Jr. 1991. Hepatocyte nuclear factor 3a belongs to a gene family in mammals that is homologous to the Drosophila homeotic gene fork head. Genes \& Dev. 5: 416-427.

Lawrence, P.A. 1981. The cellular basis of segmentation in insects. Cell 26: 3-10.

Lawrence, P.A. and G. Morata. 1976. Compartments in the wing of Drosophila: A study of the engrailed gene. Dev. Biol. 50: $321-337$.

Lee, J.L., D.P. von Kessler, S. Parks, and P. Beachy. 1992. Secretion and localized transcription suggest a role in positional signaling for products of the segmentation gene hedgehog. Cell 71: 33-50.

Li, X., T. Gutjahr, and M. Noll. 1993. Separable regulatory elements mediate the establishment and maintenance of cell states by the Drosophila segment-polarity gene gooseberry. EMBO I. 12: 1427-1436.

Macdonald, P.M., P. Ingham, and G. Struhl. 1986. Isolation, 
structure, and expression of even-skipped: A second pairrule gene of Drosophila containing a homeo box. Cell 47: 721-734.

Manoukian, A.S. and H.M. Krause. 1992. Concentration-dependent activities of the even-skipped protein in Drosophila embryos. Genes \& Dev. 6: 1740-1751.

— 1993. Control of segmental asymmetry in Drosophila embryos. Development 118: 785-796.

Martinez Arias, A. and P.A. Lawrence. 1985. Parasegments and compartments in the Drosophila embryo. Nature 313: 639642.

Martinez-Arias, A. and R.A.H. White. 1988. Ultrabithorax and engrailed expression in Drosophila embryos mutant for segmentation genes of the pair-rule class. Development 102: 325-338.

Martinez-Arias, A., N.E. Baker, and P.W. Ingham. 1988. Role of segment polarity genes in the definition and maintenance of cell states in the Drosophila embryo. Development 103: $157-170$.

Moazed, D. and P.H. O'Farrell. 1992. Maintenance of the engrailed expression pattern by Polycomb group genes in Drosophila. Development 116: 805-810.

Mohler, J. and K. Vani. 1992. Molecular organization and embryonic expression of the hedgehog gene involved in cell-cell communication in segmental patterning of Drosophila. Development 115: 957-971.

Nakano, Y., I. Guerrero, A. Hidalgo, A. Taylor, J.R.S. Whittle, and P.W. Ingham. 1989. A protein with several possible membrane-spanning domains encoded by the Drosophila segment polarity gene patched. Nature 341: 508-513.

Noordermeer, J., P. Johnston, F. Rijsewijk, R. Nusse, and P.A. Lawrence. 1992. The consequences of ubiquitous expression of the wingless gene in the Drosophila embryo. Development 116: 711-719.

Nüsslein-Volhard, C. and E. Wieschaus. 1980. Mutations affecting segment number and polarity in Drosophila. Nature 287: 795-801.

Nüsslein-Volhard, C., E. Wieschaus, and H. Kluding. 1984. Mutations affecting the pattern of the larval cuticle in Drosophila melanogaster. I. Zygotic loci on the second chromosome. Wilhelm Roux's Arch. Dev. Biol. 193: 267-282.

Orenic, T.V., D.C. Slusarski, K L. Kroll, and R.A. Holmgren. 1990. Cloning and characterization of the segment polarity gene cubitus interruptus Dominant of Drosophila. Genes \& Dev. 4: 1053-1067.

Patel, N.H., E. Martin-Blanco, K.G. Coleman, S.J. Poole, M.C. Ellis, T.B. Kornberg, and C.S. Goodman. 1989. Expression of engrailed proteins in arthropods, annelids, and chordates. Cell 58: 955-968.

Peifer, M. and A. Bejsovec. 1992. Knowing your neighbors: Cell interactions determine intrasegmental patterning in Drosophila. Trends Genet. 8: 243-249.

Poole, S.J., L.M. Kauvar, B. Drees, and T. Kornberg. 1985. The engrailed locus of Drosophila: Structural analysis of an embryonic transcript. Cell 40: 37-43.

Preat, T., P. Therond, C. Lamour-Isnard, B. Limbourg-Bouchon, H. Tricoire, I. Erk, M.C. Mariol, and D. Busson. 1990. A putative serine threonine protein-kinase encoded by the segment-polarity fused gene of Drosophila. Nature 347: 87-89.

Rijsewijk, F., M. Schuermann, E. Wagenaar, P. Parren, D. Weigel, and R. Nusse. 1987. The Drosophila homolog of the mouse mammary oncogene int 1 is identical to the segment polarity gene wingless. Cell 50: 649-657.

Rubin, G.M. and A.C. Spradling. 1982. Genetic transformation of Drosophila with transposable element vectors. Science 218: 348-353.
Saiki, R.K., S. Scharf, F. Foloona, K.B. Mullis, G.T. Horn, H.A Erlich, and N. Armheim. 1985. Enzymatic amplification of $B$-globin genomic sequences and restricition site analysis for diagnosis of sickle cell anemia. Science 230: 1350-1354.

Scott, M.P. and S.B. Carroll. 1987. The segmentation and homeotic gene network in early Drosophila development. Cell 51: 689-698.

Smith, D.B. and K.S. Johnson. 1988. Single-step purification of polypeptides expressed in Escherichia coli as fusions with glutathione S-transferase. Gene 67: 31-40.

Studier, F.W., A.H. Rosenberg, J.J. Dunn, and J.W. Dubendorff. 1990. Use of T7 RNA polymerase to direct expression of cloned genes. Methods Enzymol. 185: 60-89.

Tabata, T., S. Eaton, and T. Kornberg. 1992. The Drosophila hedgehog gene is expressed specifically in posterior compartment cells and is a target of engrailed regulation. Genes \& Dev. 6: 2635-2645.

Tautz, D. and C. Pfeifle. 1989. A non-radioactive in situ hybridization method for the localization of specific RNAs in Drosophila embryos reveals translational control of the segmentation gene hunchback. Chromosoma 98: 81-85.

Taylor, A.M., Y. Nakano, J. Mohler, and P.W. Ingham. 1993. Contrasting distributions of patched and hedgehog proteins in the Drosophila embryo. Mech. Dev. 42: 89-96.

Tearle, R. and C. Nüsslein-Volhard. 1987. Tubingen mutants and stocklist. Drosophila Inf. Serv. 66: 209-226.

van den Heuvel, M., R. Nusse, P. Johnston, and P.A. Lawrence. 1989. Distribution of the wingless gene product in Drosophila embryos: A protein involved in cell-cell communication. Cell 59: 739-749.

van den Heuvel, M., C. Harryman-Samos, J. Klingensmith, N. Perrimon, and R. Nusse. 1993. Mutations in the segment polarity genes wingless and porcupine impair secretion of the wingless protein. EMBO J. 12: 5293-5302.

Vincent, J.-P. and P.H. O'Farrell. 1992. The state of engrailed expression is not clonally transmitted during early Drosophila development. Cell 68: 923-931.

Weigel, D. and H. Jäckle. 1990. Fork head: A new eukaryotic DNA binding motif? Cell 63: 455-456.

Weigel, D., G. Jürgens, F. Küttner, E. Siefert, and H. Jäckle. 1989. The homeotic gene fork head encodes a nuclear protein and is expressed in the terminal regions of the Drosophila embryo. Cell 57: 645-658. 


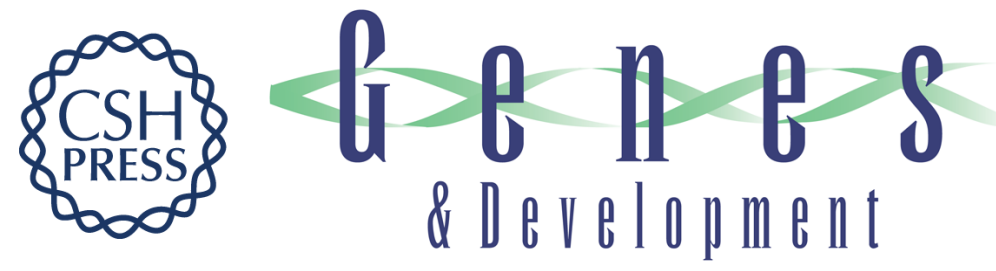

\section{Localized expression of sloppy paired protein maintains the polarity of Drosophila parasegments.}

K M Cadigan, U Grossniklaus and W J Gehring

Genes Dev. 1994, 8:

Access the most recent version at doi:10.1101/gad.8.8.899

References This article cites 82 articles, 30 of which can be accessed free at:

http://genesdev.cshlp.org/content/8/8/899.full.html\#ref-list-1

License

Email Alerting

Service

Receive free email alerts when new articles cite this article - sign up in the box at the top right corner of the article or click here.

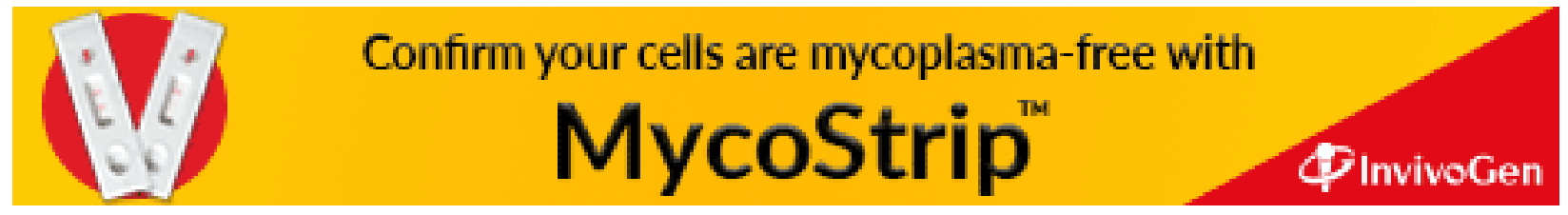

